\title{
MATERIALES PARA UNA CONFORMIDAD RESTAURATIVA
}

\author{
Daniela Gaddi*
}

\author{
"La presencia del público \\ despierta el pudor de la justicia"1.
}

Resumen: El objetivo del presente trabajo es analizar la posibilidad de dotar de significado restaurativo el mecanismo procesal de la conformidad. Para ello, se propone una reflexión sobre diferentes dispositivos de justicia negociada, analizando algunas cuestiones problemáticas. Se efectúa una comparación del significado del término consenso en la justicia negociada y en la justicia restaurativa y se identifican las condiciones para la puesta en marcha de un consenso restaurativo en el marco de las conformidades.

Recibido: junio 2020. Aceptado: octubre 2020

* Profesora Asociada de Derecho Penal y Criminología, ORCID: 00000002-2825-8551, Facultad de Derecho, Universidad Autónoma de Barcelona, C/ de la Vall Moronta, s/n. Edificio B, 08193 Bellaterra (Cerdanyola), Barcelona, Email: daniela.gaddi@uab.cat

1 "La presenza del pubblico desta il pudore della giustizia". NICOLINI, N.: Storia de' principii regolatori della istruzione delle pruove ne' processi penali. Della procedura penale nel regno delle Due Sicilie, Napoli, 1829, p. 296 [Trad. mía] 
Palabras clave: conformidad, justicia negociada, justicia restaurativa, consenso restaurativo

\section{MATERIALS FOR RESTORATIVE PLEA BARGAINING IN \\ SPAIN}

Summary: The aim of this work is to analyze the possibility of providing the Spanish procedural mechanism of "conformidad" with restorative meaning. To this end, a reflection on different negotiated justice mechanisms is first proposed, analyzing some critical issues. Then, a comparison is made of the meaning of the term consent both in negotiated justice and restorative justice, and finally the conditions for the implementation of a restorative consent in the framework of "conformidades" are identified.

Key words: "conformidad", negotiated justice, restorative justice, restorative consent

\section{Introducción}

A la espera de que se modifique finalmente la Ley de Enjuiciamiento Criminal y/o se apruebe una ley específica que se ocupe de los procesos restaurativos para integrar en el proceso penal de adultos las Directivas Europeas sobre justicia restaurativa, el instituto procesal de la conformidad ofrece hoy en día un espacio de negociación potencialmente apto para llevar a cabo procesos restaurativos. Sin embargo, a fin de examinar la posibilidad del uso "mestizo" de una figura procesal ya consolidada, que implicaría la integración entre paradigmas de justicia alternativos o complementares, es necesario dilucidar algunas cuestiones generales, a las que está dedicado este trabajo².

2 El presente trabajo ha sido realizado en el marco del Proyecto DER 2017- 84088-R "Reparación, justicia restaurativa y mediación en la delincuencia socioeconómica", financiado con fondos FEDER y por el Ministerio de Economía, Industria y Competitividad, I.P. Dra. Mercedes García Arán. 
La conformidad forma parte de aquellos mecanismos procesales que suelen denominarse con la expresión "justicia negociada", esto es, una justicia cuyo principio regulador, según se afirma, es el consenso entre las partes. Dado que el consenso entre las partes es también el principio regulador de la justicia restaurativa, ello autorizaría prima facie a formular una equivalencia entre ambos tipos de justicia. Sin embargo, como se verá a continuación, el término "consenso" se articula de manera diferente en uno y otro campo. Ello obliga a una adaptación del instituto de la conformidad que, sin renunciar a la perspectiva del sistema de justicia penal, incorpore los elementos esenciales de la justicia restaurativa. La construcción de un semejante dispositivo facilitaría el tránsito hacia la modificación restaurativa del proceso penal que viene gestándose infructuosamente desde hace ya algunos años, ofreciéndose además como un buen banco de prueba para identificar los correctivos necesarios.

\section{La justicia negociada: una aproximación de derecho com- parado}

Los términos "Justicia Negociada" se refieren, en general, a mecanismos procesales en los que Ministerio Fiscal y acusado llegan a un consenso sobre las acusaciones y las penas y/o las medidas a aplicar en el caso concreto.

Tales mecanismos en absoluto son característicos de nuestros tiempos. El juicio por "truglio" o "en concordia" vigente en la Nápoles borbónica, por ejemplo, tenía las mismas características y los mismos inconvenientes que sus descendientes modernos: "Cuando los procesos se encontraban extraordinariamente acumulados, de manera que la aplicación de la justicia se encontraba atascada por el número, a los jueces se le concedía la facultad de cerrarlos con una decisión definitiva por medio de estos procedimientos, bien con el consenso de los acusados o de oficio. Todo lo que faltaba 
se compensaba con ese cálculo de posibilidades, por el que se llevaba a cabo una suerte de transacción entre el fiscal y el abogado del reo; el fiscal aceptando una pena menor incluso con respecto a lo que resultaba probado, y el reo renunciando a su defensa, liberándose de las angustias ulteriores de la cárcel $y$ del juicio"3

El truglio, en definitiva, servía para descongestionar la justicia, acelerar los procesos e incluso favorecer la reinserción del reo, mediante la reducción de la pena o su sustitución por otras medidas ${ }^{4}$. La negociación entre Fiscal y abogado defensor se llevaba a cabo sin la publicidad del juicio y el consentimiento del acusado era indispensable, aunque podía ocurrir que se omitiera pedirlo en los casos más urgentes ${ }^{5}$.

3 "Quando i processi erano straordinariamente accumulati, sí che la spedizione della giustizia era inceppata dal numero, si concedeva facoltà a' giudici, ora col consenso de' rei, ora di ufizio, di chiuder a mezzo questi processi con una decisione diffinitiva. Tutto quello però che mancava, si suppliva con questo calcolo di possibili, tal che si faceva una specie di transazione tra il fisco, e l'avvocato del reo; il fisco condiscendendo ad una pena minore anche a fronte di ciò che si era provato, e il reo rinunziando al suo processo difensivo e sottraendosi alle ulteriori angustie del carcere e del giudizio". Así describe Nicolini el procedimiento "per truglio", implementado a partir del siglo XV y vigente en 1700 en el Reino de las 2 Sicilias. NICOLINI, 1929, cit., 290-291 [Trad. mía].

4 Por ejemplo, prestar servicio militar o prestar servicio en los buques de la Marina Real. LORUSSO, S.: "Il processo penale italiano tra prassi e consuetudine", en: MILETTI, M. N. (Ed.). Riti, tecniche, interessi: il processo penal tra Otto e Novecento (531-542). Milano: Giuffrè, 2006.

5 La misma conformidad española es un ejemplo vetusto de justicia negociada, remontándose su primera regulación a la Ley de Enjuiciamiento Criminal de 1882. Naturalmente, la búsqueda de las raíces históricas de este tipo de prácticas podría ir aún más atrás. Se podría por ejemplo ahondar en los mecanismos de la Inquisición española, estudiando el Edicto de Gracia, por el que el reo que se declarase culpable podía salvar su vida o recibir una "sentencia blanda" a cambio de su confesión, vid. DEDIEU, J.-P.: "Denunciar-denunciarse. La delación inquisitorial en Castilla la Nueva en los siglos XVI-XVII", en Revista de la Inquisición, n. 2, 1992, pp. 95-108. Lo mismo puede decirse de la "comparición espontánea", que permitía a los sponte comparentes frente a los Tribunales de la Inquisición Romana evitar el proceso o recibir una 
Algunos ejemplos "modernos" de justicia negociada son el plea bargaining y los "acuerdos de acusación diferida" (Deferred Prosecution Agreements, en adelante, DPA), vigentes sobre todo en Estados Unidos ${ }^{6}$, Reino Unido y Canadá; la Comparution sur reconnaissance préalable de culpabilité, la Convention Judiciaire d'Intérêt Public (prevista para las personas jurídicas) y la "composition pénale" en Francia; el Acuerdo entre el Tribunal y las partes en el proceso penal alemán (Verständigung zwischen Gericht und Verfahrensbeteiligten - Absprachen); la "transaction pénale" en Bélgica y la "applicazione della pena su richiesta delle parti"(así denominado "patteggiamento") en Italia.

\subsection{Países de derecho anglosajón}

El plea bargaining es sin duda la figura más célebre entre los mecanismos de justicia negociada. Consiste, a grandes rasgos, en un acuerdo entre el Fiscal y el acusado por el

pena más leve o la posibilidad de abjurar en privado. Vid.: TIGANO, M.: "La giustizia ecclesiastica del Cinquecento", en VERGENTIS, n. 5,2017 , pp. 221-239. Y finalmente, no son del todo extraños a los plea bargainings estadounidenses sus antecedentes inquisitoriales, utilizados en los procesos por brujería por los peregrinos puritanos recién llegados a las Américas. Vid., por ejemplo, KASSIN, S. M.: "False confessions: From colonial Salem, through Central Park, and into the twenty-first century", en WILLIS-ESQUEDA, C. / BORNSTEIN, B.H (Eds.), The Witness Stand and Lawrence S. Wrightsman, Jr, Springer Science + Business Media, New York, 2016, pp. 53-74.

6 En Estados Unidos existe también la posibilidad que una persona jurídica o una persona física responsable de un delito económico negocie "acuerdos de no acusación" (Non-Prosecution Agreements, de ahora en adelante, NPA) con organismos públicos, como el Ministerio de Justicia (Department of Justice) representado por un Fiscal, o la Securities and Exchange Commission. La diferencia entre los DPA y los NPA reside en el hecho de que en el segundo caso el acuerdo no implica ninguna formalidad y se resuelve privadamente entre fiscal y el acusado. Vid. MAZZACUVA, F.: "Justification and Purposes of Negotiated Justice for Corporate Offenders: Deferred and Non-Prosecution Agreements in the UK and US Systems of Criminal Justice", en The Journal of Criminal Law, n. 78, 2014, pp. 249-262. 
que este último se declara culpable a cambio de una acusación más leve o parcial, con la esperanza de obtener una pena menos dura. Concretamente, en el charge bargaining se reducen en número y/o gravedad los delitos por los que se está procediendo, mientras que en el sentence bargaining, el Fiscal "recomienda" al Juez la aplicación de una pena inferior a la prevista por el delito en cuestión. El fact bargaining implica, en cambio, que el Fiscal acepte los hechos propuestos por el acusado, renunciando a impugnar o a presentar pruebas sobre eventuales circunstancias agravantes. En algunas ocasiones, el acuerdo puede incluir el ofrecimiento de informaciones útiles para llevar a cabo ulteriores investigaciones, o el compromiso del acusado a declarar como testigo en contra de otros acusados ${ }^{7}$. Se calcula que el $90-95 \%$ de las causas en los EE. UU. se resuelven a través de acuerdos negociados de este tipo ${ }^{8}$.

En cuanto a los $D P A$, que fueron desarrollados al principio en los EE. UU. para la delincuencia leve o juvenil, se aplican hoy en día principalmente a la delincuencia corporativa en países como EE. UU., Gran Bretaña y Canadá. Se trata de acuerdos entre la acusación pública y la persona jurídica, en virtud de los cuales el fiscal acepta diferir o renunciar a la acusación si, en un determinado periodo de tiempo, la corporación cumple con algunas obligaciones. A diferencia del plea bargaining, estos mecanismos no requieren la admi-

7 Vid., entre otros, LANGER, M.: "Plea Bargaining, Conviction Without Trial, and the Global Administratization of Criminal Convictions", en Annual Review of Criminology, n. 4, 2021, pp. 1.1-1.35, review in advance disponible en: https://www.annualreviews.org/doi/pdf/10.1146/ annurev-criminol-032317-092255; CRESPO, A.M.: "The Hidden Law of Plea Bargaining”, en Columbia Law Review, n. 118, 2018, pp. 1303-1424; RODRÍGUEZ GARCÍA, N.: "Aproximación al estudio de la justicia penal negociada de los EE.UU.: The Plea Bargaining Process", en REDEN: Revista Española De Estudios Norteamericanos, n. 9, 1995, pp. 91-107.

8 RODRÍGUEZ GARCÍA, 1995, cit. Vid. también DAVIS, A. J.: "The Prosecutor's Ethical Duty to End Mass Incarceration”, en Hofstra Law Review, Vol. 44, n. 4, 2016, pp. 1063-1085. 
sión de culpabilidad (non plea settlements). Las obligaciones convenidas pueden consistir en prestaciones tan diferentes como, por ejemplo, pagar una multa, compensar a la víctima, hacer donaciones en dinero en favor de alguna organización benéfica, devolver el enriquecimiento injusto o implementar un programa de cumplimiento9. Si la corporación no cumple con las obligaciones, el Fiscal puede solicitar la apertura del juicio. En los EE. UU., la Oficina del Fiscal General suele hacer público mediante comunicados de prensa el contenido de los acuerdos alcanzados a través de los DPA y NPA ${ }^{10}$.

\subsection{Países de derecho continental}

Análogos mecanismos de justicia negociada se han difundido también en los Países de derecho continental, sobre todo como expresión de una oportunidad reglada, en virtud de la que se permite dejar a la negociación entre las partes el resultado del procedimiento penal, bajo determinadas condiciones.

\subsubsection{Francia}

En Francia, son ejemplo de ello las Comparution sur reconnaissance préalable de culpabilité (en adelante, CRPC) y la Convention Judiciaire d'Intérêt Public (en adelante, CJIP) ${ }^{11}$. Esta última figura, instaurada en 2016, es la versión francesa del DPA anglosajón y se aplica a las personas jurídicas, sobre todo en caso de delitos fiscales y de algunas figuras de corrupción. Este procedimiento, que permite imponer a la persona jurídica una serie de obligaciones ${ }^{12}$ y que tiene

9 MAZZACUVA, 2014, cit.

10 XIAO, M. Y.: "Deferred/Non Prosecution Agreements: Effective Tools to Combat Corporate Crime", en Cornell Journal of Law and Public Policy, Vol. 23, n.1, Article 7, 2013, pp. 233-253. Disponible en: http:// scholarship.law.cornell.edu/cjlpp/vol23/iss1/7

11 GALLI, M.: "Une justice pénale propre aux personnes morales. Réflexions sur la convention judiciaire d'intérêt public", en Revue de science criminelle et de droit pénal comparé, Vol. 2, n. 2, 2018, pp. 359-385.

12 Concretamente, el pago de una multa de "interés público" (calculada sobre la base del enriquecimiento y en todo caso no superior al $30 \%$ de 
lugar antes de que se ponga en marcha la acción pública, no requiere que la persona jurídica se declare culpable y evita la inscripción en el registro de los antecedentes penales. De este modo, la persona jurídica podrá continuar participando en futuras convocatorias para la contratación pública. En el caso en que exista una víctima identificable, se le informa de la intención del Fiscal de proponer una CJIP y se le otorga la posibilidad de aportar informaciones acerca de lo sucedido y del daño padecido (Art. 41-1-2, I, C.P.P.). La puesta en marcha de la Convention requiere la aprobación del Presidente del Tribunal en una vista pública. La decisión, así como el mismo acuerdo, se comunica al público mediante una nota de prensa del Fiscal y se publica en la página web de la Agencia Francesa Anticorrupción ${ }^{13}$.

En cuanto a la CRPC, denominada también plaidercoupable, se trata de una medida aplicable a los delits sancionados con penas de hasta 5 años de prisión, con la exclusión de algunas figuras específicas ${ }^{14}$. Consiste en un acuerdo entre el Fiscal y la defensa, posteriormente homologado por el juez, en el que el acusado se declara culpable, recibiendo a cambio una pena más leve ${ }^{15}$. La victima tiene derecho a

la media de las entradas anuales de los últimos 3 años), la aplicación de un programa de cumplimiento bajo el control de la Agencia Francesa Anticorrupción (AFA) por un máximo de 3 años y la reparación de los daños sufridos por las posibles víctimas, cuando éstas puedan ser identificadas (Artículo 41-1-2, C.P.P.).

13 LE PROCUREUR DE LA REPUBLIQUE FINANCIERE, AGENCE FRANÇAISE ANTICORRUPTION: Lignes directrices sur la mise en æuvre de la Convention Judiciaire d'Intérêt Public, 2019, disponible en: https://www.agence-francaise-anticorruption.gouv.fr/files/files/ Lignes $\% 20$ directrices $\% 20$ PNF\%20CJIP.pdf

14 En el código penal francés los délits son figuras de gravedad intermedia con respecto a los crimes (que son más graves) y las contraventions (que son más leves)

15 La expresión "leve" se refiere tanto a la duración y al tipo de la pena a cumplir, como a la desgravación de determinadas consecuencias (por ejemplo, la no aplicación de una inhabilitación) (Art. 495-8, C.P.P). 
recibir informaciones sobre la puesta en marcha de la CRPC. Asimismo, puede pedir una indemnización como parte civil y tiene un cierto peso en la homologación final de acuerdo ${ }^{16}$, si bien no participa directamente en las negociaciones entre Fiscal y acusado. Los porcentajes de aplicación de esta medida, aunque al alza, no son especialmente significativos: en 2016, por ejemplo, se ha aplicado en el 13\% de las condenas correccionales y en el $24 \%$ de las condenas resultantes de procedimientos simplificados ${ }^{17}$.

Otro mecanismo negociado presente en la legislación francesa es la "composition pénale", en la que, antes de la apertura del procedimiento, el acusado se declara culpable y acepta la sanción propuesta por el Ministerio Fiscal ${ }^{18}$, evitando así el juicio. El acuerdo, en este caso, no requiere la homologación del juez. Se aplica tanto a las personas físicas como a las jurídicas y está prevista para los délits menos graves y las contraventions, en aquellos casos en los que el Fiscal considera que esta medida "puede proporcionar una reparación del daño causado a la víctima, poner fin al desorden resultante del delito o contribuir a la rehabilitación del autor" (Art. 41-1 C.P.P.). La victima tiene derecho a recibir información sobre la propuesta del Fiscal y la conclusión de la medida y conserva su derecho a reclamar la indemnización por

16 El Presidente del Tribunal puede rechazar el acuerdo "si la situación de la víctima o los intereses de la sociedad justifican una audiencia correccional ordinaria o cuando las declaraciones de la víctima en virtud del artículo 495-13 arrojan nueva luz sobre las condiciones en las que se cometió el delito o sobre la personalidad del autor" (Art. 495-11-1, C.P.P.).

17 HOULLE, R. / VANEY, G.: "La comparution sur reconnaissance préalable de culpabilité, une procédure pénale de plus en plus utilisée”, en INFOSTAT JUSTICE, n. 157, 2017, pp. 1-8, disponible en: http://www. justice.gouv.fr/art_pix/stat_Infostat_157.pdf

18 Entre ellas, una multa, o la obligación de reparar el daño causado a la víctima, de realizar trabajos en beneficio de la comunidad, o de participar en talleres de formación sobre violencia doméstica o abuso de estupefacientes, el retiro del carné de conducir, algún tipo de inhabilitación $\mathrm{o}$, incluso, la participación en un proceso de mediación con la víctima (art. 41-1, C.P.P.). 
la vía civil. En 2017, apenas un 10\% de los casos se concluyó con una composition penale ${ }^{19}$.

\subsubsection{Bélgica}

En Bélgica, la "transaction pénale" autoriza el Fiscal a ofrecer al acusado la posibilidad de evitar el juicio o de poner fin al proceso, mediante el abono de una suma de dinero o la renuncia a determinados bienes o beneficios patrimonia$\operatorname{les}^{20}$. Se trata de un mecanismo extraprocesal, dirigido tanto a personas físicas como jurídicas, aplicable a los delitos que implican penas de hasta 5 años. No requiere el reconocimiento de la culpabilidad, y permite evitar la inscripción en el registro de los antecedentes penales. En 2011, su alcance se ha extendido a delitos más graves, siempre y cuando la víctima no haya sufrido daños físicos, y se ha incentivado su uso para los delitos económicos y corporativos. Según se observa, su aplicación no es todavía muy extendida ${ }^{21}$. En 2018, el legislador introdujo una serie de garantías y controles jurisdiccionales, además de la obligación, para el Fiscal, de motivar sus peticiones.

\subsubsection{Alemania}

En Alemania, la posibilidad de Acuerdo entre el tribunal y las partes en el procedimiento (Verständigung zwischen Gericht und Verfahrensbeteiligten, secc. 257, c) del Código

19 CHAMBAZ, C. (dir.): Les chiffres-clés de la Justice 2018. Ministère de la Justice, Sous-direction de la Statistique et des Études, Paris, 2018, disponible en: http://www.justice.gouv.fr/art_pix/justice-chiffres-cles-2018. pdf. En el caso de las contraventions y de ciertos délits, el Fiscal tiene también la posibilidad de proponer a las partes una mediación como alternativa al proceso.

20 Junto con la transaction pénale, la legislación belga también contempla la posibilidad de la mediación victima-infractor.

21 FERNANDEZ-BERTIER, M.: "The extension of the Belgian criminal transaction as a new mean to fight economic and financial crime: towards the establishment of plea bargaining?" En NEVES CRUZ, J. et.al. (Coords.): Infrações económicas e financeiras : estudos de criminologia e direito, Coimbra : Coimbra Editora, 2013, pp. 484-494. 
Procesal Penal, conocidos como Absprachen) fue originariamente introducida en el 2009 y su constitucionalidad fue confirmada en 2013, con algunas limitaciones ${ }^{22}$, aunque, en realidad, las negociaciones informales en el marco de la justicia penal eran ya una práctica común desde mucho tiempo antes $^{23}$, incluso para delitos económicos, delitos fiscales y/o ambientales $^{24}$. El procedimiento de Absprachen consiste en un "entendimiento" entre el juez y las partes, en el que el juez, basándose en informaciones suficientes acerca de los hechos, propone que se inicie una negociación, indicando el límite mínimo y máximo que podría imponer por el delito en cuestión. El fallo final no es objeto de negociación y, en consecuencia, el juez tiene que avisar previamente al acusado de que la sentencia final podría diferir del acuerdo si emergieran nuevos elementos factuales o legales ${ }^{25}$. No se trata en este caso de un mecanismo alternativo al ejercicio de la acción penal, sino más bien de un procedimiento que permite reducir los tiempos del juicio.

Se ha sugerido que una de las razones por las que este tipo de procedimiento pudo abrirse camino en el sistema

22 WEIGEND, T. / TURNER, J. I.: "The Constitutionality of Negotiated Criminal Judgments in Germany", en German Law Journal, Vol. 15, n. 1, 2014, pp. 81-105. Como en Francia y en Bélgica, la ley procesal penal alemana también establece la posibilidad de llevar a cabo encuentros de mediación entre víctima y ofensor, lo que permite al juez mitigar o no imponer la pena si el acusado se ha esforzado por reparar el daño o compensar a la víctima (Parágrafo 46a, StPO).

23 Incluso la práctica de llevar a cabo negociaciones informales sobre la confesión (confession agreements) era frecuente, aunque no declarada, desde la década de los '70. Vid. SWANSON, T.: "The German 'Plea Bargaining' Debate", en Pace International Law Review, Vol. 7, n. 2, 1995, pp. 373-429, disponible en: https://digitalcommons.pace.edu/pilr/vol7/iss2/4

24 FROMMANN, M.: "Regulating Plea-Bargaining in Germany: Can the Italian Approach Serve as a Model to Guarantee the Independence of German Judges?", en Hanse Law Review, Vol. 5, n. 1, 2009, pp. 197-220.

25 AMBOS, K. et al. (2020): Core Concepts in Criminal Law and Criminal Justice: Anglo-German Dialogues, Volume 1, Cambridge: Cambridge University Press, 2020. 
alemán fue el incremento de los delitos económicos, que requieren de unos conocimientos y de unas herramientas de investigación especialmente sofisticadas ${ }^{26}$.

La víctima no puede intervenir en los Absprachen, salvo que se haya personado en el proceso como Nebenkläger (acusación suplementaria). Solamente como Nebenkläger, pues, la víctima tiene el derecho a recibir información sobre las negociaciones, así como a ser escuchada y a expresar su opinión acerca del acuerdo, aunque no tiene derecho de veto $^{27}$.

\subsubsection{Italia}

El "patteggiamento" es la expresión más significativa de la justicia negociada en Italia. En este procedimiento, las partes pueden, conjunta o individualmente, presentar al juez una petición para la aplicación de una determinada pena, disminuida hasta 1/3. El objeto del acuerdo, por tanto, es la pena y no el contenido de las acusaciones o la calificación del delito, como en el plea bargaining anglosajón. Otra especificidad del procedimiento italiano es que, en caso de disenso del Fiscal, el juez también puede "aceptar" la propuesta del acusado, si le parece suficientemente fundamentada (art. 448 C.p.p.). En todo caso, la aceptación o la petición del acusado no implican una admisión explícita de culpabilidad. Con varias modificaciones desde su introducción en 1988, el legislador italiano ha ido, por un lado, progresivamente ampliando los márgenes de aplicación de este instrumento, elevando los límites de pena. Por el otro, ha introducido algunas importantes limitaciones, vetando su uso en el caso de delitos considerados especialmente graves o estableciendo el necesario y previo cumplimiento de algunas condiciones. Es éste, por ejemplo, el caso de los delitos contra la Administración Pública, en los que la posibilidad

26 WEIGEND, T.; TURNER, Jenia I., 2014, cit.

27 AMBOS et al., 2020, cit. 
de acceder al patteggiamento queda subordinada a la restitución del "provecho" del delito (prezzo o profitto del reato), o de los delitos fiscales, que requieren como condiciones procesales de admisibilidad el pago integral de la deuda o el ravvedimento operoso ${ }^{28}$. Se ha advertido que estas condiciones acarrean serias dificultades, entre otras que no siempre es posible determinar la naturaleza económica del "provecho" del delito, o el daño patrimonial causado a la Administración Pública, así como no siempre está claro a quién debería restituirse (y qué) en aquellos casos en los que la víctima, además de ser la Administración Pública, es un particular (el concusso) o cuando haya perjudicados "secundarios". Estas dificultades harían especialmente difícil, en este tipo de delito, acceder al patteggiamento ${ }^{29}$.

El patteggiamento no prevé, al menos por el momento, ninguna forma de participación de la víctima, aunque algunos interpretan las obligaciones restitutorias antes mencionadas como un guiño a la justicia restaurativa, especialmente en el ámbito de los delitos cometidos por funcionarios públicos ${ }^{30}$.

\subsubsection{España}

Cabe finalmente mencionar, aunque rápidamente, el instituto español de la conformidad, que consiste, a grandes rasgos, en la aceptación por parte del acusado de la calificación del Fiscal, o de las calificaciones más graves, si hubiera otros acusadores, generalmente recibiendo a cambio una rebaja de la pena. La aceptación, que se refiere a los hechos, a la pena y a la responsabilidad civil, queda recogida en la calificación de la defensa o en una calificación conjunta del Fiscal y de la defensa, y está sometida al control

28 PERONI, F.: "La peripezia del patteggiamento in un trentennio di sperimentazione", en Archivio Penale, n. 3, 2019, pp. 1-23.

29 VERGINE, F.:"Il patteggiamento: gli obblighi restitutori depotenziano le finalità deflattive", en Processo penale e giustizia, n. 2, 2019, pp. 443-449.

30 VERGINE, 2019, cit. 
jurisdiccional. El juez puede en efecto rechazar el acuerdo, cuando considere que la decisión del acusado de adherir a la propuesta del Fiscal no ha sido libre o que los hechos no han sido apropiadamente calificados o que la pena indicada no es la procedente. En estos casos, el juez acuerda la continuación del juicio. El juicio deberá también continuar, aunque limitadamente a este aspecto, cuando no se haya alcanzado un acuerdo sobre la responsabilidad civil.

La víctima puede participar en las negociaciones, mediante la representación de su abogado, solamente si se ha personado en el proceso como acusación particular. En este caso, puede proponer su propia calificación y, en el procedimiento abreviado, tiene derecho a expresar su opinión acerca de la suspensión o la sustitución de la pena impuesta. Por el contrario, cuando la víctima no se ha personado en el proceso, su papel se circunscribe a la posibilidad de que se le notifique por escrito la sentencia de conformidad (art. 789.4 LECrim $)^{31}$. En todo caso, el Fiscal debe oírla previamente y, en lo posible, informarla del resultado de la conformidad, aunque no esté personada en la causa ${ }^{32}$.

Las sentencias por conformidad representan la solución más frecuente de los procesos penales en España. Se calcula que alrededor de un $70 \%$ de las sentencias emitidas en el 2018, tanto condenatorias como absolutorias, fueron en conformidad con la posición del Fiscal, concretamente el $70 \%$ en los Juzgados de lo Penal y el 71\% ante las Audiencias Provinciales. En los juicios rápidos, las conformidades han llegado en 2018 a representar el 90\% de las sentencias condenatorias ${ }^{33}$.

31 AGUILERA MORALES, M.: "Víctima y conformidad: Al encuentro de dos rectas paralelas llamadas a coincidir", en DE HOYOS SANCHO, M.: La víctima del delito y las últimas reformas procesales penales, Pamplona: Aranzadi, 2017, pp. 99-119.

32 FISCALÍA GENERAL DEL ESTADO: Instrucción 2/2009.

33 FISCALÍA GENERAL DEL ESTADO: Memoria de la FGE 2019, Madrid. 


\section{Algunas características comunes a los procesos de justicia negociada}

Como se ha podido observar en esta breve descripción, los mecanismos de justicia negociada permiten evitar, abreviar o simplificar el proceso judicial, renunciando a la acción penal o permitiendo que las partes dispongan de ella, en mayor o menor medida, según el ordenamiento jurídico de referencia.

A pesar de sus diferencias sustanciales y/u operacionales, todos estos dispositivos procesales comparten algunos aspectos problemáticos. Mencionamos aquí, aunque no son las únicas, cuestiones como el hecho de sustentarse en una lógica instrumental, de llevarse a cabo en la más absoluta "discreción" (falta de transparencia), de representar una amenaza potencial para los principios fundamentales que gobiernan el proceso penal, de ser especialmente excluyentes con respecto a la víctima y de estar gobernados por el principio del consenso ${ }^{34}$.

\subsection{La lógica instrumental}

El aspecto más destacado en la literatura sobre justicia negociada es su conveniencia para mejorar las prestaciones del sistema judicial. De hecho, se ha puesto de manifiesto insistentemente que estos procedimientos permiten descongestionar unos tribunales sofocados por el incremento desproporcionado de causas judiciales. La necesidad de abordar el "colapso" del sistema judicial convertiría a estos instrumentos en algo deseable o, en todo caso, en un "mal necesario" 35 . Tiempos más breves y agilización de los procedimientos $^{36}$ favorecerían además el ahorro de recursos

34 Otras características señaladas frecuentemente, que aquí no se examinan, son su predisposición para fomentar la privatización de la justicia o para minar la confianza pública en el sistema de justicia.

35 JOHNSON, T.: "Public perceptions of plea bargaining", en American Journal of Criminal Law, Vol. 46, Fasc. 1, 2019, pp. 133-156.

36 Permiten, por ejemplo, evitar el juicio por razones de "utilidad", según GÓMEZ COLOMER, J.-L.: "Notas sobre la justicia procesal (alterna- 
económicos y facilitarían las investigaciones criminales ${ }^{37}$, haciendo el sistema de justicia penal más rápido y eficiente, en beneficio de todos los actores del mismo: fiscales, abogados, víctima e infractores.

Concretamente, se afirma que ello es así porque el Fiscal tiene asegurado el éxito ${ }^{38}$, evitando al mismo tiempo invertir su tiempo en pesadas investigaciones ${ }^{39}$, mientras que los abogados pueden alcanzar un resultado favorable para sus asistidos y pasar a dedicarse a otros asuntos en un tiempo relativamente breve ${ }^{40}$. Del acusado se sostiene que, además de conseguir una pena reducida, logra importantes beneficios en términos de su reinserción social, dado que la justicia negociada reduce los tiempos de la detención preventiva y de la pena, además de asegurar, al mismo tiempo, efectos positivos desde el punto de vista de la prevención general positiva $^{41}$. Por otro lado, se alega que la víctima puede obtener un

tiva, negociada, transaccional, activa reparadora). Un nuevo sistema de justicia para aliviar al sistema de justicia judicial", en CASTILLEJO MANZANARES, R. (Dir.): Justicia restaurativa y violencia de género. Más allá de la Ley Orgánica 1/2004, Universidad de Santiago de Compostela, 2014, pp. 170-199.

37 Ello sería, por ejemplo, uno de los beneficios de la conformidad. Vid. FERRÉ OLIVÉ, J.C.: "El Plea Bargaining, o cómo pervertir la justicia penal a través de un sistema de conformidades low cost", en Revista Electrónica de Ciencia Penal y Criminología, 20-06, 2018, pp. 1-30.

38 KING, C. I LORD, N.: Negotiated Justice and Corporate Crime. The Legitimacy of Civil Recovery Orders and Deferred Prosecution Agreements, Palgrave Pivot, 2018.

39 RODRÍGUEZ GARCÍA, 1995, cit.

40 RODRÍGUEZ GARCÍA, 1995, cit.

41 FERRÉ OLIVÉ, 2018, cit. El beneficio para los acusados en las conformidades consistiría en ver "finalizado el proceso de forma más ágil y consensuada", según se afirma en el Protocolo entre Fiscalía General y Abogacía Española (punto 3). Vid. Protocolo de actuación para juicios de conformidad suscrito entre la Fiscalia General el Estado y el Consejo General de la Abogacía Española, Madrid, a 1 de abril de dos mil nueve. Disponible en: http://www.poderjudicial.es/cgpj/es/Temas/ Relaciones-institucionales/Convenios/Protocolo-de-actuacion-parajuicios-de-conformidad-suscrito-entre-la-Fiscalia-General-del-Estadoy-el-Consejo-General-de-la-Abogacia-espanola. 
resultado rápido y cierto, frente a una alternativa aleatoria y dilatada en el tiempo como es el juicio ${ }^{42}$ y pueden también acceder a la reparación del daño padecido "de forma ágil y segura" ${ }^{43}$.

Se destaca también la utilidad de la justicia negociada para perseguir delitos de índole especialmente compleja y, por tanto, más difíciles de investigar mediante los procedimientos "ordinarios", como por ejemplo los delitos económicos ${ }^{44}$.

42 Aunque frente a muchas desventajas, advierte AGUILERA MORALES, 2017, cit.

43 Protocolo entre Fiscalía General y Abogacía Española, 2009, (punto 3)

44 Por ejemplo, la CJIP francesa respondería a la exigencia específica de establecer mecanismos más eficaces de lucha en contra de la corrupción, en un contexto delictivo en el que es especialmente difícil recabar pruebas y en un país que no dispone de mecanismos adecuados para abordar la responsabilidad penal de las personas jurídicas. Vid. VERGÈS, E.: "Procédure pénale", en Revue de science criminelle et de droit pénal comparé, Vol. 3, n. 3, 2017, pp. 579-586. La CJIP permitiría un tratamiento más rápido y eficaz, facilitando y simplificando el trabajo judicial, siempre que no se reduzca su uso a un simple indicador de eficiencia, también según HOULETTE, É.: "Des dispositifs répressifs innovants : la convention judiciaire d'intérêt public, le monitoring, la peine de programme de mise en conformité", en Actes de Colloque De la conformité à la justice négociée, actualité de la lutte anticorruption, École Nationale de la Magistrature, Paris, 17 de mai 2018, pp. 41-42. Disponible en: https://www.enm.justice.fr/sites/default/ files/actu-pdf/Actes-du-colloque_De-la-conformite-a-la-justice-negociee. pdf. Ello encontraría confirmación en las Líneas Guía para la aplicación de la CJIP, en las que se indica que el interés público puede considerarse satisfecho cuando la medida, además de garantizar la indemnización de los prejuicios causados a la víctima o la prevención de la reincidencia, permite "reducir el tiempo de la investigación" y "asegurar la efectividad y la firmeza de la respuesta judicial". Vid. LE PROCUREUR DE LA REPUBLIQUE FINANCIERE, AGENCE FRANÇAISE ANTICORRUPTION, 2019, cit. p. 6. Asimismo, se ha señalado que, al ampliar los márgenes de la transaction penale, la intención del legislador belga fue la de permitir su aplicación a los delitos económicos, para superar las dificultades inherentes a su persecución y agilizar los procedimientos, así como en general aligerar las cargas de los tribunales. Vid. FERNANDEZ-BERTIER, 2013, cit. También en la introducción de los Absprachen alemanes, como antes se ha mencionado, se 
La capacidad de fomentar una mayor agilidad de los juicios se predica también de la conformidad española. En el Protocolo de actuación para juicios de conformidad suscrito entre la Fiscalía General el Estado y el Consejo General de la Abogacía Española, se afirma, por ejemplo, que "los medios de solución consensuada del proceso penal [...] se orientan prioritariamente a fomentar la celeridad y a simplificar los trámites precisos para alcanzar la sentencia dispuestos por la Ley de Enjuiciamiento Criminal especialmente desde la reforma de la Ley Orgánica 15/2003." (punto 1). Asimismo, se sostiene que el Protocolo puede ayudar a descongestionar los juzgados, reduciendo su colapso y permitiendo una mejor programación de las actividades judiciales ${ }^{45}$.

Por otra parte, la Fiscalía General del Estado, en su Instrucción 2/2009, relativa a la Aplicación del Protocolo mencionado, se refiere a los mecanismos de justicia negociada como a "pulmones de oxígeno que explican y permiten la supervivencia de nuestra maquinaria procesal decimonónica" 46. En este sentido, el enjuiciamiento de quien se declare culpable es visto como innecesario, frente a los beneficios logrados por una "solución consensuada del proceso", por ejemplo, el de economizar el tiempo y el trabajo necesarios para preparar

vio una manera de aligerar la carga de los tribunales, sobrellevar las limitaciones económicas y superar las dificultades de encontrar las pruebas en los casos más complicados. Vid. CHEESMAN, Samantha J.: "Comparative Perspectives on Plea Bargaining in Germany and the U.S.A.”, en BADÓ, A.; BELLING, D.W (Eds). Rechtsentwicklungen aus europäischer Perspektive im 21. Jahrhundert, Potsdam: Universität Potsdam, 2014, pp. 113-151, disponible en: https://publishup.uni-potsdam.de/opus4-ubp/frontdoor/deliver/index/docId/7046/file/aiup02.pdf.

45 Protocolo entre Fiscalía General y Abogacía Española, 2009, cit.

46 FISCALÍA GENERAL DEL ESTADO, Instrucción 2/2009 sobre Aplicación del protocolo de conformidad suscrito por la Fiscalía General del Estado y el Consejo General de la Abogacía española, p. 2. Disponible en http://www.poderjudicial.es/cgpj/es/Temas/Relacionesinstitucionales/Convenios/Protocolo-de-actuacion-para-juicios-deconformidad-suscrito-entre-la-Fiscalia-General-del-Estado-y-elConsejo-General-de-la-Abogacia-espanola. 
el juicio. En consonancia con lo expresado, los convenios de ejecución del Protocolo, firmados por las diferentes Fiscalías del Estado y los Colegios de Abogados correspondientes, también se refieren a las conformidades como una herramienta útil para la descongestión del sistema judicial, que beneficia a todos los actores implicados ${ }^{47}$.

Ahora bien, no todos comparten esta visión optimista de la justicia negociada y algunos cuestionan abiertamente la conveniencia real de su implementación. Así, hay quienes observan que la lógica instrumental sobre la que estas medidas se sostienen entraría en contradicción con los fundamentos mismos de la acción pública, haciendo del Fiscal y del acusado meros "agentes económicos racionales" de una justicia basada en criterios de máxima eficacia, de conveniencia y de gestión del riesgo ${ }^{48}$. Otros opinan que el "deseo irrefrenable" de aligerar las cargas judiciales lleva el legislador a trocar calidad por velocidad, en un procedimiento donde al oportunismo comprensible del acusado se suma el oportunismo del Estado, preocupado más de contener los tiempos y los costes que de garantizar la calidad del proceso pena ${ }^{49}$. Por otro lado, se ha señalado el riesgo que entraña, en términos de confianza pública, de equidad y de justicia, el favorecer medidas que van dirigidas más a solucionar problemas o a lograr castigos de forma más efectiva, que a esclarecer la verdad ${ }^{50}$.

47 Vid., por ejemplo, el Conveni d'Execució Protocol Conformitats de Barcelona, del 26.3.2010: "Esta anticipación procesal también tiene efectos beneficiosos para los imputados y para las víctimas, dado que el conflicto social producido se puede solucionar en menos tiempo, sin que tengan que padecer el efecto estigmatizador del juicio y con efectos más positivos en relación a la resocialización, y por lo que se refiere a las víctimas, se verán reparadas moral y económicamente, en los casos en que proceda, de manera más inmediata" (p. 3) [trad. mía].

48 VERGÈS, 2017, cit., p. 583.

49 CECANESE, G.: "Ancora dubbi irrisolti in tema di applicazione della pena su richiesta delle parti", en Archivio Penale, n. 1, 2015, pp. 1-25, p. 22.

50 Véase la investigación de JOHNSON, 2019, cit., además de DAVIS, A. J.: "Prosecution and Race: The Power and Privilege of Discretion", en Fordham Law Review, Vol. 67, n. 1, 1998, pp. 13-68. 
Merece señalar finalmente que hay voces críticas también con respecto al argumento del "colapso" del sistema judicial, algunas de ellas tempranas ${ }^{51}$. Se ha observado, entre otras cosas, que, pese a las reformas implementadas hasta ahora (orgánicas, procedimentales y de las instituciones procesales), el argumento de la crisis de la justicia sigue dominando los debates ${ }^{52}$. Por lo tanto, es razonable pensar que los beneficios declarados de la justicia negociada no son realmente tales, o al menos no lo son de una forma tan evidente $^{53}$ y que basarse en el potencial "agilizador" de estas medidas $^{54}$ para justificar su implementación no es acertado ni oportuno.

En todo caso, basar la acción jurisdiccional sobre una lógica instrumental puede comprometer los principios mismos del proceso penal, además de incentivar la falta de transparencia y reafirmar la posición subordinada de la víctima, como veremos a continuación.

\subsection{El riesgo de vulneración de los principios funda-} mentales

Un efecto especialmente pernicioso de querer impulsar la justicia negociada por meras finalidades de economía procesal es el riesgo de menoscabar los principios fundamentales del derecho penal y procesal.

51 Vid. por ejemplo NADER, L.: "The ADR Explosion - The Implications of Rhetoric in Legal Reform", en Windsor Yearbook of Access to Justice, n. 8, 1988, pp. 269-281.

52 GÓMEZ-COLOMER, J.-L.: "La conformidad, institución clave y tradicional de la justicia negociada en España”, en Revue Internationale de Droit Pénal, Vol. 83, n. 1, 2012, pp. 15-41, disponible en: https://www. cairn.info/revue-internationale-de-droit-penal-2012-1-page-15.htm\#

53 En todo caso, los factores que podrían haber dado lugar al incremento de causas judiciales apenas son objeto de análisis.

54 Como se ha hecho con las conformidades pactadas en España, según AGUILERA MORALES, M.: "La deriva del principio del consenso", en Revista Ítalo-Española de Derecho Procesal, 2, 2019, pp. 1-18, p. 4. 
Algunos autores denuncian, por ejemplo, que la justicia negociada supone el avance de una justicia administrativa en la que las garantías procesales pierden fuerza ${ }^{55}$, cuando no son abiertamente violadas, con la consecuente producción masiva de condenas sin beneficio real alguno para el acusado o para la sociedad ${ }^{56}$.

Otros evidencian que resultarían afectados los principios de legalidad, de igualdad, de defensa, así como la indisponibilidad de la acción penal ${ }^{57}$, en lo que se ha definido como una forma hibrida de justicia, un mecanismo profundamente impregnado por el espíritu consensualista del derecho contractual ${ }^{58}$.

En este sentido, se señala que la asimetría entre Ministerio Fiscal y defensa, en términos de acceso a la información y de la calidad técnico-jurídica de las alegaciones ${ }^{59}$, determina resultados injustos y decisiones poco afortunadas por parte de los acusados. Al respecto, no son pocos los autores que advierten que la justicia negociada obliga a acusados inocentes a declararse culpables frente a la posibilidad de afrontar un juicio cuyo resultado es incierto ${ }^{60}$. Este problema ha sido señalado también respecto a las conformidades

55 KING, C.; LORD, N., 2018, cit.

56 JOHNSON, 2019, cit.

57 KING, C.; LORD, N., 2018, cit.; FERRÉ OLIVÉ, 2018, cit.; CECANESE, 2015, cit.; GÓMEZ COLOMER, 2014, cit.; RODRÍGUEZ ARIAS, A.M.: "Principio de oportunidad, justicia negociada y posición de las partes en el proceso penal”, en Revista de Derecho y Proceso Penal, n. 56, 2019, pp. 161-198.

58 El carácter "civilistico" de esta institución procesal emerge, según Vergès, incluso en el uso del lenguaje por parte del legislador, que sustituye el término "delito" con el término "incumplimiento". Ver VERGÈS, 2017, cit.

59 FERRÉ OLIVÉ, 2018, cit.

60 JOHNSON, 2019, cit.; para una reseña, vid. también FERRÉ OLIVÉ, 2018, cit., y LESTER, B.J.: "System Failure: The Case for Supplanting Negotiation with Mediation in Plea Bargaining", en Ohio State Journal on Dispute Resolution, Vol. 20, n. 2, 2005, pp. 563-595. 
españolas. Se resalta concretamente que la posibilidad de condenar a un inocente no es una hipótesis descabellada porque los criterios utilitaristas que están detrás de la conformidad hacen peligrar las garantías procesales y los derechos constitucionales del acusado ${ }^{61}$.

Otro aspecto que se ha criticado es la discrecionalidad del Fiscal y su poder casi "monopolístico" en las negociaciones que resulta incompatible con la necesidad de asegurar un proceso justo ${ }^{62}$. Como señala Davis, en los EE. UU. el poder discrecional del Fiscal es de tal magnitud que prácticamente le permite determinar de antemano el resultado de la mayoría de las causas penales ${ }^{63}$, ampliando así las tasas de encarcelamiento en ese país ${ }^{64}$. En el contexto español, el Fiscal no dispone ciertamente del mismo grado de discrecionalidad. Sin embargo, se señala que en la práctica el control jurisdiccional sobre la conformidad no se ejerce con todas las cautelas que serían necesarias y que deberían establecerse mecanismos de supervisión más efectivos ${ }^{65}$.

Por su parte, Aguilera Morales observa que los acusados disconformes pueden ver comprometido su derecho de defensa y correr además el riesgo de recibir un trato más desfavorable, pudiendo resultar agravada su situación en la sentencia ${ }^{66}$. También algunos autores alemanes han afirmado que, en estos casos, la negativa a conformarse podría traducirse en una sentencia más severa, aunque es difícil discernir si ello se debe a la negativa o a la apreciación de las circunstancias del delito y del acusado ${ }^{67}$. Otros autores

\footnotetext{
61 RODRÍGUEZ ARIAS, 2019, cit.

62 LESTER, 2005, cit.

63 DAVIS, A. J.: "In Search of Racial Justice: The Role of The Prosecutor ", en Legislation and Public Policy, n. 16, 2013, pp. 821-851.

64 DAVIS, 2016, cit.

65 RODRÍGUEZ ARIAS, 2019, cit.. También FERRÉ OLIVÉ, 2018, cit.

66 AGUILERA MORALES, 2019, cit.

67 CHEESMAN, 2014, cit.
} 
finalmente han evidenciado que este tipo de procedimiento favorecería aquellos acusados que tienen "algo que ofrecer", propiciando así situaciones de desigualdad en el proceso ${ }^{68}$.

\subsection{La falta de transparencia}

La falta de transparencia, cuando no el secretismo, que suele caracterizar este tipo de procedimientos es otro aspecto vinculado a la lógica instrumental. Ante todo, el hecho de que las negociaciones se lleven a cabo en un contexto extraprocesal y que el control judicial, cuando lo hay, se limite al resultado final y no se extienda a las fases de negociación, daría pie a todo tipo de iniquidad ${ }^{69}$. Se trata de un aspecto que es objeto de numerosos reproches, tanto en el contexto anglosajón ${ }^{70}$ como en los países de derecho continental. En Italia se critica, por ejemplo, que las negociaciones del patteggiamento se llevan a cabo "en la sombra" y que por ello es especialmente necesario tutelar el efectivo derecho de defensa del imputado ${ }^{71}$. Asimismo, Aguilera Morales observa que el carácter oculto de las negociaciones que se realizan en el marco de las conformidades españolas permitiría prácticas que se concretan en un verdadero "fraude procesal" 72 . Merece recordarse que la antes mencionada Instrucción 2/2009 de la FGE invita a preservar la "confidencialidad" de las negociaciones, específicamente de aquellas que se realizan inmediatamente antes del juicio oral, frente a la posibilidad de que el juez pueda escuchar las conversaciones y que su imparcialidad pueda quedar mermada. Aunque se entienden las razones de esta argumentación, es necesario advertir que el argumento de la confidencialidad podría generalizarse hasta

68 FERRÉ OLIVER, 2018, cit.

69 La falta de supervisión llevaría a resultados injustos en la mayor parte de los casos según LESTER, 2005, cit.

70 Ver, por ejemplo, lo expuesto por JOHNSON, 2019, cit.

71 En un "cono d'ombra", PERONI, 2019, cit., p. 23.

72 Lo que conlleva especial prejuicio para los coacusados que deciden no conformarse. Vd. AGUILERA MORALES, 2019, cit. 
el punto de convertirla en una justificación para la falta de transparencia de las negociaciones, tanto de las que se llevan a cabo minutos antes del juicio, como de las que se realizan con más antelación. De igual modo, merece señalarse que el "plan de choque", previsto para afrontar el colapso que el sistema judicial pueda sufrir como consecuencia de la conclusión del estado de alarma, prevé que las sentencias de conformidad puedan dictarse oralmente, sin otra documentación que la fundamentación registrada en soporte audiovisual ${ }^{73}$. Ello parece configurar la imposibilidad fáctica de acceder a las decisiones fruto de las conformidades negociadas, ya de por si poco circunstanciadas, además de ofrecer un ejemplo de cuán fácilmente estos procedimientos se pueden emplear para "aliviar" las cargas de los tribunales.

Una segunda manifestación de la falta de transparencia es la posición subordinada del acusado y de la víctima, cuya participación es meramente residual, dado que quien negocia son mayoritariamente el Fiscal y el abogado defensor ${ }^{74}$.

Un tercer aspecto se refiere a la disparidad entre Fiscal y defensa en cuanto al acceso a las informaciones. En este sentido, se ha observado que generalmente el Fiscal puede disponer de informaciones que quedan ocultas para el abogado, lo que repercute negativamente en la posibilidad de elaborar una defensa adecuada ${ }^{75}$.

73 COMUNICACIÓN PODER JUDICIAL (7 de abril de 2020). El CGPJ reúne un centenar de medidas en un documento base preparatorio del plan de choque para evitar el colapso de la Justicia tras el fin del estado de alarma. Disponible en: http://www.poderjudicial.es/cgpj/es/ Poder-Judicial/En-Portada/El-CGPJ-reune-un-centenar-de-medidasen-un-documento-base-preparatorio-del-plan-de-choque-para-evitarel-colapso-de-la-Justicia-tras-el-fin-del-estado-de-alarma.

74 De nuevo, este aspecto está presente tanto en los países anglosajones como en los contextos de derecho continental. Vid., por ejemplo, JOHNSON, 2019, cit.

75 Además de en EE. UU., también en Alemania estas prácticas se llevarían a cabo en detrimento de acusados privados de informaciones. Vid. CHEESMAN, 2014, cit. 
Un último elemento problemático es la invisibilidad de este tipo de procedimientos para el público en general. Como observa Johnson, en el imaginario popular es el juicio, entendido como contienda entre partes que presentan pruebas y contraargumentan, el que constituye el corazón del sistema judicial penal, mientras que en la realidad es muy poco frecuente que se celebren juicios propiamente dichos $^{76}$. Ello no solamente puede predicarse de los EE. UU sino también de los países de derecho continental donde el público no experto está más familiarizado con el juicio que con los procedimientos de justicia negociada. Ello es así porque generalmente los medios de comunicación ofrecen noticias sobre aquellos eventos que, por su gravedad, no permiten una gestión negociada. Incluso personas con un nivel de estudios elevado suelen desconocer la existencia de las conformidades, mientras que pueden ofrecer una descripción razonablemente correcta de cuáles son las fases de un proceso penal ordinario ${ }^{77}$. Precisamente para contribuir a publicitar y dar a conocer esta institución se publican online los acuerdos, por ejemplo, en EE. UU. y Francia.

\subsection{La exclusión de las víctimas}

Como se ha mencionado anteriormente, las víctimas tienen la posibilidad de defender sus intereses en un procedimiento de justicia negociada solamente si se han personado como acusación particular en el proceso. Cuando esto no sucede, algunos países obligan el Fiscal a informarlas de la existencia y/o del resultado de las negociaciones.

Sin embargo, una cosa es la disposición normativa y otra, bien distinta, es la realidad de su aplicación. En este

76 FERRÉ OLIVÉ, 2018, cit.. En el mismo sentido, FLYNN, A. I FREIBERG, A.: Plea negotiations, Palgrave Socio-Legal Studies, 2018, que describen la situación de las negociaciones en Australia.

77 Ello emerge de las primeras evidencias de un estudio destinado a profundizar sobre la percepción de estas formas de justicia en Cataluña, que se está llevando a cabo en estos momentos. 
sentido, se ha observado que, en la mayoría de los casos, la víctima no es consciente de lo que está ocurriendo, ni tiene la posibilidad de intervenir ${ }^{78}$. Por un lado, en un sistema cada vez más orientado según criterios utilitaristas, las víctimas se convierten en un estorbo. Por el otro lado, nuestros sistemas de justicia no están construidos para dar entrada a las alocuciones legas, a menos de traducirlas en los términos propios del contexto procesal, y esto tiende a provocar una disociación semántica entre los discursos técnicos del Fiscal y de los abogados y las representaciones de los hechos que la víctima (además del acusado) intenta o quisiera proponer. La consecuencia para la víctima es que los acuerdos negociados casi nunca reflejan sus necesidades, o al menos no las reflejan del todo, puesto que únicamente se toman en consideración aquellas susceptibles de ser indemnizables.

Pero, como reiteradamente advierten los estudios de victimología, las necesidades de las víctimas no se limitan a las exigencias económicas y abarcan además múltiples dimensiones. En la dimensión del proceso, por ejemplo, las víctimas necesitan que se les otorgue un papel más activo, en lugar de ser tratadas como un mero objeto del procedimiento. Necesitan además recibir información y ser consultadas, necesitan que su versión se tenga en cuenta a la hora de tomar una decisión y necesitan tener algún grado de control sobre lo que está pasando ${ }^{79}$. Es por esta razón por la que para la víctima no es lo mismo un acuerdo en el que se reconozca la realidad de su experiencia, que un acuerdo que contiene una versión "aligerada" de los hechos vividos. De ahí la importancia de incorporar a la víctima en las negociaciones, además de su

78 JOHNSON, 2019, cit. La autora refiere el ejemplo del célebre caso de Jeffrey Epstein, el empresario estadounidense acusado de tráfico y abuso de menores de edad, en el que ninguna de las víctimas fue notificada del resultado final de las negociaciones ni del contenido de la sentencia.

79 TEN BOOM, A.; KUIJPERS, K. F.: "Victims' needs as basic human needs", en International Review of Victimology, Vol. 18, n. 2, 2012, pp. 155-179. 
abogado, para que el acuerdo sea compatible con la representación propuesta por todos los actores implicados ${ }^{80}$.

Esas advertencias, como es sabido, están encontrando cada vez más reconocimiento, también a nivel legislativo ${ }^{81}$. Sin embargo, en los procedimientos de justicia negociada la víctima generalmente sigue sin tener la posibilidad de expresarse, se encuentra en una posición especialmente débil y se ve privada del juicio, es decir, de la única posibilidad de obtener alguna forma de reconocimiento ${ }^{82}$.

80 VERDUN-JONES, S.N / TIJERINO, A.A.: "Four Models of Victim Involvement during Plea Negotiations: Bridging the Gap between Legal Reforms and Current Legal Practice", en Revue Canadienne de Criminologie et de Justice Penal, Vol. 46, n. 4, 2004, pp. 471-500. Los autores identifican 4 posibles modelos de implicación de la víctima, dependiendo del grado de su participación. En el primero la víctima mantiene un rol del todo pasivo: tiene el derecho de recibir información sobre la causa solamente si lo requiere y su punto de vista puede ser tenido en consideración tan sólo si la policía o el tribunal lo creen oportuno. En el segundo modelo se añade la posibilidad de que la víctima pida informaciones acerca de eventuales procesos de negociación que se estén llevando a cabo. En este caso el fiscal puede consultar a la víctima sobre los términos de los posibles acuerdos negociados, pero en ningún caso la víctima puede participar directamente en la negociación. Un rol más activo es el que la víctima tiene en el tercer modelo. En este caso, el acuerdo debe ser aprobado en una vista oral por un juez, que podrá contar con informe técnico sobre el caso para formar su decisión. A su vez la víctima podrá prestar su declaración, oralmente o por escrito, en la vista dedicada a la aprobación del acuerdo. El Fiscal deberá informar a la Corte de sus esfuerzos para informar a la víctima de la posibilidad de presentarse a la vista, así como del punto de vista de la víctima misma. En el cuarto modelo, de momento solamente hipotético, la víctima tendría el derecho de vetar el acuerdo fruto de las negociaciones.

81 Directiva 2012/29/UE del Parlamento Europeo y del Consejo de 25 de octubre de 2012 por la que se establecen normas mínimas sobre los derechos, el apoyo y la protección de las víctimas de delitos, y por la que se sustituye la Decisión marco 2001/220/JAI del Consejo y Ley 4/2015, de 27 de abril, del Estatuto de la víctima del delito. Esta última, por ejemplo, ha creado las Oficinas de Asistencia a las Víctimas (artt. 27, 28 y 29) y establecido un mecanismo de evaluación individual de las víctimas a fin de determinar sus necesidades especiales de protección (artt. 23 y 24).

82 WEIGEN / TURNER, 2014, cit.. También el patteggiamento supondría una merma de los derechos de las víctimas, según CECANESE, 2015, cit. 
Por lo que concierne la realidad española, se observa que, a diferencia de los acusados y del sistema de justicia, las victimas no se beneficiarían en modo alguno de la conformidad, ni tan siquiera en términos de reparación. Según Aguilera Morales, aunque parte de la doctrina sostenga que una de las finalidades de la conformidad es la reparación del daño, ello tan sólo encuentra cumplimiento en los muy poco frecuentes casos en los que la víctima está presente en las negociaciones ${ }^{83}$. Pese al deber de información que la Instrucción 2/2009 le ha impuesto, queda en las manos del Fiscal valorar si el informar a la víctima es necesario y oportuno, basándose en criterios como la relevancia de los intereses en juego o la especial vulnerabilidad de la víctima. En la práctica, son muy pocos los casos en los que el Fiscal consulta la víctima y, cuando lo hace, es solamente porque la víctima puede ofrecerle informaciones útiles para llevar a cabo las negociaciones ${ }^{84}$. La misma opinión expresa Rodríguez Arias, quien observa que en la mayoría de las conformidades a la víctima no se la interpela, ni se le explica el contenido del acuerdo alcanzado ${ }^{85}$. Además, critica el autor la idea de que la conformidad es beneficiosa para la víctima porque no la expone al trauma del juicio, visto que la gran mayoría de las conformidades se alcanzan poco antes de que empiece el juicio oral, es decir, cuando la víctima ya ha pasado por la conmoción de todas las fases anteriores ${ }^{86}$.

\section{El principio del consenso en la justicia negociada y en la justicia restaurativa}

Se suele afirmar que los mecanismos de justicia negociada son expresión del principio del consenso, por basarse

83 AGUILERA MORALES, 2017, cit.

84 AGUILERA MORALES, 2017, cit.

85 RODRÍGUEZ ARIAS, 2019, cit.

86 RODRÍGUEZ ARIAS, 2019, cit. 
en un acuerdo de tipo cuasi contractual entre el Fiscal y el acusado, en el que ambos obtienen algún beneficio ${ }^{87}$.

La justicia restaurativa también se basa en el consenso para alcanzar sus objetivos: basta pensar en la omnipresente mención al "dialogo" entre infractor y victima como mecanismo para alcanzar acuerdos reparatorios.

El consenso, en definitiva, es un principio regulador de ambos tipos de proceso y es sobre este aspecto procedimental sobre el que quisiera centrar mi atención.

\subsection{La justicia negociada: el "asentir"}

En la justicia negociada, el término consenso se refiere al resultado de una interacción en la que una de las dos partes "asiente" a la propuesta de la otra. Poco importa ahora establecer si este asentimiento es un requisito formal o fáctico: el esquema en todo caso requiere un decir que sí/ un aceptar en el marco de una relación asimétrica.

La conformidad también, como su nombre lo indica, es una mera adhesión a la propuesta del Fiscal. Ello es evidente cuando el acusado acepta la calificación acusatoria del Fiscal, pero también en los casos en los que se presenta al juez el escrito de calificación conjunto, por la asimetría obvia entre acusación y defensa, que no permite una transacción en condiciones de igualdad ${ }^{88}$.

Este mismo asentir asimétrico, con todas sus consecuencias, ha sido repetidamente certificado en todos los

87 En semejante contexto, el consenso se reduce a un mero instrumento de economía procesal. Vid. IGARTUA LARAUDOGOITIA, I.: "Significación de la reparación, compensación o restauración en la administración de justicia penal. Retórica y práctica de la justicia penal negociada y la justicia penal restaurativa", en Revista Aranzadi Unión Europea, 10, 2016, pp. 65-84.

88 En estos casos, el acusado puede a lo sumo "rascar algo" de la negociación, pero a ello precisamente no debería denominársele "consenso", por ser una de las dos voluntades forzada a postular con todos los medios a su disposición. 
procesos de justicia negociada que hemos mencionado al principio de este trabajo.

Otro aspecto típico del consenso negociado es que, como indicamos anteriormente, los únicos legitimados para participar en las conversaciones son el Ministerio Fiscal y el abogado del acusado o, a veces, el de la víctima. En muy contadas ocasiones es el mismo acusado quien directamente interviene en la negociación.

Este tipo de negociaciones, además, tiene un carácter altamente "competitivo", esto es, en ellas cada parte se esfuerza para lograr el máximo beneficio para si, en detrimento de la otra. Cada parte tiene intereses y objetivos propios. El Fiscal quiere lograr rápidamente un resultado positivo, quiere asegurarse la condena, quiere recabar más informaciones para sus investigaciones. En definitiva, actúa más con vistas a sus propios intereses, que preocupado de los intereses públicos ${ }^{89}$.Por su parte, el acusado trata de rebajar su pena, o de evitar el juicio por la razón que sea, mientras que su abogado defensor quiere resolver rápidamente el asunto, usualmente por el mismo precio, y pasar a otro cliente $^{90}$.

Para ganar la contienda, se usa todo tipo de estratagemas negociales. Por ejemplo, se ocultan informaciones, se amenaza con imponer penas más altas de lo que correspondería para asegurarse márgenes de maniobra, se aprovecha de un asesoramiento legal desafortunado y/o deficiente, se usa la presión del tiempo para desconcertar a la parte más débil. El típico contexto de "tomar o dejar" propio de este

89 Como se ha observado por la realidad alemana, la falta de público alentaría esta actitud "personalista" del Ministerio Fiscal. Vid. CHEESMAN, 2014, cit.

90 Ferré Olivé observa que los abogados deben prepararse para aplicar estrategias de negociación en un contexto en el que lo más importante no es la aplicación de la pena como resultado de un proceso justo, sino lograr la mejor gestión del riesgo posible. Vid. FERRÉ OLIVÉ, 2018, cit. 
tipo de mecanismos procesales puede incluso determinar un clima de coerción, con acusados detenidos, mantenidos en condiciones de estrés o privados de informaciones ${ }^{91}$. Todo ello, según señala Ferré Olivé, termina por producir decisiones poco racionales ${ }^{92}$.

También en el marco de nuestra investigación sobre justicia restaurativa y delitos económicos, los entrevistados han puesto en evidencia cómo en las conformidades se suele negociar "jugando" con las atenuantes: reparación, dilaciones o algún aspecto vinculado al abuso de drogas o alcohol.

El mero asentimiento, la exclusión de algunos de los interesados directos y el empleo de estratagemas negociales representan un ejemplo de lo que Habermas define como "acciones estratégicas". Esto es, acciones en las que un sujeto persigue lograr sus fines particulares egoístamente y en solitario, sin tener un real interés en llegar a un acuerdo con su contraparte ${ }^{93}$. El accionar estratégico objetiviza el interlocutor, es decir, lo transforma en un mero elemento a tener en cuenta para la ejecución de un plan de acción individual ${ }^{94}$. Entonces, el interlocutor adquiere relevancia solamente en cuanto medio para alcanzar objetivos personales, de manera que su punto de vista pierde importancia, a menos que no pueda utilizarse instrumentalmente.

En este contexto, el empleo de estratagemas negociales resta sentido al entendimiento mutuo y, por ende, a la

91 CHEESMAN, 2014, cit.

92 FERRÉ OLIVÉ, 2018, cit.. También Rodríguez Arias observa además que, en la práctica procesal, no son pocas las ocasiones en las que los fiscales proponen penas más duras, para asegurarse un margen de ventaja en la negociación. Ello conlleva además que, de no alcanzarse el acuerdo, la condena será más elevada. Vid. RODRÍGUEZ ARIAS, 2019, cit.

93 HABERMAS, J.: Teoría de la Acción Comunicativa, Vol. I, Ed. Taurus: Madrid, 1987.

94 HABERMAS, J.: Verdad y justificación, Ed. Trotta Madrid, 2002 (ed. or. 1999). 
construcción de consenso. Por ejemplo, cuando se utilizan amenazas, tanto explícitas como implícitas, la causa de la decisión del interlocutor no es el consenso, si no el temor a padecer las consecuencias planteadas. Si en la amenaza se omite la mención a las consecuencias, el efecto de adhesión no se produce. Se trata, por lo tanto, de una forma de ejercer el poder, influenciando la decisión del otro. En estos casos, la intención de los participantes en la conversación no es la de alcanzar un acuerdo "bona fide", sino la de lograr un resultado deseado ${ }^{95}$.

Es por ello por lo que, según Habermas, los acuerdos alcanzados a través de procesos de negociación, a pesar de ser aceptables, no son racionales. Se trataría de llegar a "arreglos", a "conciertos", más que a un entendimiento mutuo real. Entonces, para que la negociación resulte justa (fair), esto es, no gobernada por las intenciones estratégicas de las partes, es necesario regularla: "Así, por ejemplo, el poder de negociación no neutralizable ha de quedar al menos disciplinado mediante su equidistribución entre las partes. En la medida en que la negociación de compromisos discurra conforme a procedimientos que aseguren a todos los interesados iguales oportunidades de participar en las negociaciones y durante las negociaciones les otorguen iguales oportunidades de ejercer mutuamente influencia unos sobre otros y, por tanto, en términos generales, creen también iguales oportunidades para que se hagan valer todos los intereses afectados, en la medida, digo, en que se den estas condiciones, habrá base para presumir que los acuerdos y arreglos a que se llega son fair." ${ }^{.96}$.

95 HABERMAS, J.: On the Pragmatics of Communication, The MIT Press, Cambridge, 1998 (ed. por COOKE Maeve). Vid. también NIEMI, J. I.: "Jürgen Habermas's theory of communicative rationality: the foundational distinction between communicative and strategic action", en Social Theory and Practice, Vol. 31, n. 4, 2005, pp. 513-532

96 HABERMAS, J.: Facticidad y validez., Ed. Trotta, Madrid, 1998 (ed. or. 1992-1994), pp. 234-235. 
Así es como se puede garantizar la ecuanimidad de los resultados. Por consiguiente, Habermas ha planteado la necesidad de regular jurídicamente las negociaciones, persuadido de la necesidad de limitar las actitudes estratégicas de los contendientes, llegando a sugerir una reglamentación que incide profunda y directamente en el proceso (identificación de los participantes, sus derechos, duración, turnos de intervención, temas, etc.).

\subsection{La justicia restaurativa: el "consensuar"}

A diferencia de en la justicia negociada, donde el consenso se concibe como mera adhesión, en la justicia restaurativa el consenso deriva de un proceso de construcción de un sentido común, es decir, es expresión de un consensuar $^{97}$. En otros términos, es el resultado de una interacción comunicativa en la que las partes van construyendo la solución de forma colaborativa, desde una posición de relativa simetría, con el objetivo de llegar a un acuerdo común sobre la mejor forma de reparar el daño que el delito ha provocado.

Los actores legitimados para intervenir en este tipo de encuentros varían según el tipo de proceso restaurativo, pero, al contrario que en la justicia negociada, siempre comprenden al menos el infractor, la víctima (o alguna figura sustitutoria) y un tercero que acompaña el proceso. Uno de los fundamentos de la justicia restaurativa, por lo tanto, es que requiere de la presencia de las personas directamente implicadas: la sustitución del infractor y de la víctima por sus abogados, en este tipo de procesos, no tiene ningún sentido. Ello naturalmente no significa que los abogados no puedan estar presentes, siempre y cuando su presencia sea respetuosa de las reglas que gobiernan el intercambio restaurativo.

97 Como puede observarse, ello representa de manera fiel el origen de la palabra "consensus", en la que la preposición "cum" implica unión, compañía. Assensus, en cambio, implica un asentimiento, una aprobación o adhesión que no implica alguna puesta en común. 
Otro aspecto a tener en cuenta es que el consenso restaurativo no concierne tanto la pena cuanto el significado que el evento-delito ha tenido y/o tiene para cada uno de los participantes en el encuentro. No se trata por lo tanto de establecer la culpabilidad y seleccionar el castigo correspondiente. Se trata de reconstruir el sentido del evento delictivo de manera que pueda ser compartido por todos los protagonistas y, sobre esa base, establecer conjuntamente la forma mejor de reparar sus consecuencias. Es por ello por lo que un encuentro restaurativo incluye forzosamente una pluralidad de actores legitimados para tomar la palabra.

Así las cosas, gracias también a la intervención de un tercero garante de la ecuanimidad del proceso, el contexto en que se realizan los encuentros restaurativos tiene una naturaleza cooperativa y evita el ocultamiento de informaciones o el uso de amenazas o presiones.

Según algunos autores, ello permitiría calificar los encuentros restaurativos como formas de "acción comunicativa", en sentido habermasiano. A diferencia de las estratégicas, las acciones comunicativas son, para Habermas, acciones orientadas al entendimiento y al acuerdo. La interacción comunicativa es una situación en la que los actores coordinan sus planes de acción de forma dialógica, con el uso de la argumentación ${ }^{98}$. La convicción común que se genera a través de la comunicación implica la aceptación tácita de las obligaciones necesarias para la acción futura. En este sentido, dice Habermas, "la convicción común crea un nuevo hecho social." "99. La creación de un vínculo normativo entre las partes, vehiculada por la interacción dialógica, es proba-

98 En palabras de Habermas, es una acción en la que las partes tienen “... el propósito de llegar a un acuerdo que sirva de base a una coordinación concertada de los planes de acción individual'. Cfr. HABERMAS, 1987, ob. cit., p. 379.

99 HABERMAS, 1998, Facticidad y validez, ob. cit., p. 215. 
blemente una de las razones más importantes de la solidez de los acuerdos alcanzados en mediación ${ }^{100}$.

Sobre esta base, algunos consideran la mediación como la "antesala de la acción comunicativa", viendo en ella un instrumento de justicia restaurativa que basa sus intervenciones en una racionalidad de este tipo ${ }^{101}$. Ello es así porque el mediador vela por la simetría, la razonabilidad, la igualdad y por la corrección del acuerdo, además de contener las derivas instrumentales y corregir los equilibrios de poder. En definitiva, haría realidad que "el potencial de la razón dialógica despliegue sus efectos pacificadores." ${ }^{102}$.

\subsection{Las razones para optar por un consenso restaurativo}

Si bien tenemos dudas fundamentadas acerca de la calidad "comunicativa" de las interacciones que se llevan a cabo en los encuentros restaurativos ${ }^{103}$, es importante que al menos no se incentive el uso de acciones estratégicas en el proceso penal, porque es precisamente este actuar estratégico, que se manifiesta en el encuentro de dos "oportunismos", lo que determina todos los problemas a los que nos hemos referido supra.

100 GADDI, D.: La mediación reflexiva como mecanismo de regulación social (Tesis doctoral). Barcelona: Universitat Autònoma de Barcelona, 2017, ISBN 9788449068720. Disponible en <https://ddd.uab.cat/ record/174014>

101 CARABANTE MUNTADA, J. M.: "La teoría de la acción comunicativa como modelo de mediación", en RODRÍGUEZ-ARANA MUÑOZ, X. / DE PRADA RODRÍGUEZ, M. (coords.), La mediación: presente, pasado y futuro de una institución jurídica (35-46), España: Netbliblo, 2010, pp. 35-46, p. 46.

102 CARABANTE MUNTADA, 2010, cit., p. 46. En el mismo sentido, vid. también BONAFÉ-SCHMITT, J.-P.: "Les médiations", en Communication et organisation, n. 11, 1997, disponible en: http://communicationorganisation.revues.org/1914, y BONAFÉ-SCHMITT, J.-P.: "Los mediadores: el actuar comunicacional", en La Trama, n. 18, 2006.

$103 \mathrm{Al}$ menos, en la acepción habermasiana del término. Vid. GADDI, 2017, cit. 
Por consiguiente, frente a procesos negociales que no incluyen a los implicados directos, que están dirigidos a lograr resultados estratégicos (la condena/la rebaja de pena y/o la descongestión del sistema judicial), que no ofrecen ninguna garantía de transparencia de los intercambios y/o de los resultados durante las negociaciones, es preciso tomar en consideración la posibilidad de instaurar, también en el marco de las conformidades, procesos basados en un consenso restaurativo, es decir, un consenso fruto del "consensuar".

Ante todo, ello permitiría a la víctima salir de su posición de subordinación, dado que en una conformidad restaurativa se convertiría en un participante necesario, en consonancia con los principios establecidos por la Directiva Europea 2012/29/UE, de 25 de octubre, y ratificados en el Estatuto de la Víctima ${ }^{104}$. El Estatuto de la Víctima parece incluso establecer un auténtico derecho de acceso a los servicios de justicia restaurativa ${ }^{105}$. Sin embargo, en la práctica, aunque en el campo penal la locución "Justicia Restaurativa" se use con desenvoltura, su aplicación concreta es todavía muy limitada, al menos en el ámbito de adultos. Aquí, los Programas de Justicia Restaurativa que, pese a carecer de una reglamentación específica, se han implementado en todo el territorio nacional, aún se ocupan fundamentalmente de delitos menores y con muy poca frecuencia se los emplea para las conformidades. Así las cosas, promover la intervención directa de las víctimas en las negociaciones contribuiría a materializar su derecho a la participación activa en el proceso penal.

En segundo lugar, con la aplicación del principio del consenso restaurativo, la lógica instrumental sobre la que se han construido las conformidades se diluiría. Ello es

104 Ley 4/2015, de 27 de abril, del Estatuto de la Victima del Delito. Vid. por ejemplo el Titulo II, sobre la participación de la víctima en el proceso penal.

105 Estatuto de la Víctima, art. 15 "Servicios de justicia restaurativa". 
así porque el foco se desplazaría desde los objetivos individuales del Ministerio Fiscal y de la defensa hacia el objetivo de lograr soluciones compartidas, esto es, construidas a partir de las necesidades de todos los implicados (incluido el sistema de justicia penal). La justicia restaurativa, como explica Varona, "es una justicia que no es rápida ni productivista, sino más bien sosegada y procedimental" 106 . Aunque es razonable pensar que también los procesos de justicia restaurativa podrían contribuir a descongestionar los Tribunales ${ }^{107}$, este no es su objetivo primordial sino, a lo sumo, un efecto secundario.

Además, los intentos estratégicos de las partes encontrarían un freno en la introducción de un tercero cuya tarea es, como vimos, la de equilibrar las asimetrías. El uso de amenazas y/o la prevalencia de asentimientos basados en el temor a consecuencias peores pasarían de ser la regla a ser la excepción, reduciéndose así también el riesgo de menoscabar los principios fundamentales del proceso.

Finalmente, al ampliarse el número de participantes, también mejoraría la transparencia de las negociaciones, porque al control jurisdiccional sobre el acuerdo se sumaría la supervisión de todo el procedimiento, tanto por parte del tercero facilitador, como por parte de los directos interesados.

\section{Hacia una conformidad restaurativa}

La idea de utilizar el espacio de la conformidad para la realización de encuentros restaurativos cuenta ya con

106 VARONA, G.: "Justicia restaurativa y justicia terapéutica: hacia una praxis reflexiva de transgresiones disciplinares", en PILLADO GONZÁLEZ, E. (Dir.): Hacia un proceso penal más reparador y resocializador: avances desde la justicia terapéutica, Dickynson, Madrid, 2019, pp. $25-55$, p. 32.

107 IGARTUA LARAUDOGOITIA, 2016, cit., y RODRÍGUEZ ARIAS, 2019, cit. 
algún respaldo doctrinal y con algunas esporádicas experiencias prácticas ${ }^{108}$.

A ello alude Aguilera Morales, por ejemplo, cuando afirma que la finalidad de reparación del daño se realizaría solamente en las conformidades espontáneas o en las conformidades que son fruto de un acuerdo reparador alcanzado por las partes en mediación ${ }^{109}$. También Ferré Oliver, aunque sin llegar a proponer su uso restaurativo, observa que la única conformidad admisible sería aquella capaz de asegurar a las partes "libertad de negociación dentro de los márgenes legales y no un mero contrato de adhesión en el que se toma o se deja la oferta realizada desde la Fiscalía" ${ }^{110}$.

Por otro lado, ha habido ya también alguna experiencia de campo. En un artículo dedicado a la descripción de los resultados de la intervención del servicio de Mediación Penal de Madrid, Pascual Rodríguez se refiere a 4 casos (sobre 218), derivados durante la fase de instrucción, en los que la mediación ha dado lugar a conformidades ${ }^{11}$. Otras experiencias en este sentido han sido relatadas también por las Fiscales entrevistadas en el marco de nuestra investigación sobre justicia restaurativa y delitos económicos. Aunque se haya

108 Una idea análoga ha sido aludida también para el marco del patteggiamento italiano. Vid. MANNOZZI, G.: "Il crimine dei colletti bianchi: profili definitori e strategie di contrasto attraverso i metodi della giustizia riparativa", en SPINELLIS, C.D. / THEODORAKIS, N. / BILLIS, E. / PAPADIMITRAKOPOULOS, G. (Eds). Europe in crisis: crime, criminal justice, and the way forward. Essays in honour of Nestor Courakis. Vol. II, Ant. N. Sakkoulas Publishers L.P., Athens, 2017, pp. 1365-1394.

109 AGUILERA MORALES, 2017, cit.

110 FERRÉ OLIVÉ, cit., p. 17.

111 PASCUAL RODRÍGUEZ, E.: "La experiencia práctica de la mediación penal en Madrid", en MARTÍNEZ ESCAMILLA, M.; SÁNCHEZ ÁLVAREZ, M. P. (Coords.). Justicia restaurativa, acción penal y penitenciaria: un renovado impulso, Madrid, Reus, 2011, pp. 361-392. La autora examina los casos trabajados desde el enero del 2006 hasta el diciembre del 2010. 
tratado de casos muy puntuales, y precisamente ninguno de ellos relacionado con delitos económicos, las representantes de la Fiscalía se han mostrado satisfechas con los resultados, llegando a afirmar que la mediación llevada a cabo había resultado de gran utilidad para enfocar y resolver el caso de la mejor manera, además de respetuosa de las exigencias del sistema de justicia y de las garantías del acusado.

En definitiva, la idea va gradualmente abriéndose camino y es por ello por lo que es oportuno comenzar a explorar algunas directrices que puedan servir de base para la construcción de un protocolo de actuación en esta materia.

Sobre la base de todo lo expuesto en este trabajo, mi propuesta va hacia una conformidad en la que los acuerdos sean el fruto de reuniones restaurativas supervisadas y dirigidas por un facilitador ${ }^{112}$, en las que participen no solamente el Fiscal y los abogados, sino también el acusado y la víctima personalmente. Los acuerdos estarían sometidos al mismo control jurisdiccional previsto actualmente para las conformidades negociadas. Asimismo, para asegurar su transparencia, deberían publicarse, al menos en sus elementos esenciales, en la página web de la Fiscalía y del Consejo General del Poder Judicial, en un apartado dedicado expresamente a ello.

El proceso empezaría por iniciativa bien del acusado, de la víctima, del Fiscal o del Juez, quienes se dirigirían para ello a un servicio especializado en justicia restaurativa. Sería el mismo servicio de justicia restaurativa el encargado de averiguar si en el caso señalado existen las condiciones técnicas para llevar a cabo un encuentro restaurativo. Si tales condiciones no se dieran, el proceso de negociación seguiría su cauce ordinario. Esta última eventualidad debería supeditarse a la imposibilidad absoluta de realizar reuniones restaurativas.

112 Utilizamos el término más general de "facilitador" en lugar de "mediador", porque la mediación es tan sólo una de las formas en que se pueden realizar los encuentros restaurativos. 
Dado que la justicia restaurativa requiere de la participación de todos los interesados y que este tipo de encuentros se llevaría a cabo en el marco procesal, es necesario que estén representados también los intereses del sistema penal. La presencia del Fiscal sería por lo tanto imprescindible. Proponer encuentros restaurativos en el marco de las conformidades sin su participación podría sin duda favorecer soluciones satisfactorias para las partes, pero tales soluciones tendrían pocos o nulos efectos, si después el Fiscal no las hiciera propias en el escrito de acusación. Además, sin su presencia, se debería plantear una negociación sucesiva para que pudiera valorar las soluciones propuestas, lo que representaría una duplicación muy poco operativa de todo el procedimiento. Ahora bien, la participación de la Fiscalía en los encuentros restaurativos requiere que se regule la asimetría entre ésta y el acusado, por tanto, sería necesario revisar parcialmente sus funciones. En una conformidad restaurativa, la tarea del Fiscal consistiría en enfocar los hechos traduciéndolos en los términos proprios del derecho penal, aclarando a las partes las consecuencias jurídicas de sus propuestas, así como su aceptabilidad desde la perspectiva del sistema penal, y proponiendo alternativas que tuvieran en cuenta los intereses tanto del acusado como de la víctima. Para ello, debería tener una formación específica en justicia restaurativa, que le permitiera conjugar las características propias de su acción con las exigencias del proceso restaurativo.

En cuanto al papel del facilitador, su actividad se concretaría en la prestación de servicios de interés público en el marco de la administración de la justicia. Debería por tanto establecerse la creación de servicios pertenecientes a la Administración de la Justicia con la presencia de personal funcionario especializado, o la incorporación a la Administración de los servicios externalizados actualmente existentes. Solamente así al facilitador podría reconocérsele la legitimidad para "gobernar" un proceso en el que tendría también la función de equilibrar la asimetría existente entre Fiscal y acusado. Además de su competencia en materia de 
justicia restaurativa, el facilitador debería profundizar en el conocimiento del derecho penal y procesal, para poder evaluar correctamente el significado, alcance y consecuencias de las acciones de las partes y saberlas interpretar y abordar también a la luz de las exigencias del sistema de justicia penal.

La propuesta desde luego entraña algunas dificultades, sobre las que habrá que seguir trabajando. Algunas de ellas están vinculadas a la presencia del Fiscal en el encuentro restaurativo. Por ejemplo, deberían establecerse garantías para el caso en que durante la reunión emergieran otros elementos acusatorios.

Asimismo, debería aclararse hasta qué punto la participación del acusado en el proceso restaurativo podría interpretarse como una admisión de responsabilidad en el caso en que las partes no lleguen a ningún acuerdo. Además, debería encontrarse una solución al problema de los coacusados disconformes.

Otro de los problemas se encuentra en el modo en qué se debería regular aquellos casos en los que resulta imposible contactar con la víctima, o ésta no quiere participar. Análoga dificultad plantean los delitos sin víctima a menos que se admita la participación de algún tipo de victima sustitutoria o representativa ${ }^{113}$.

También hay que tener en cuenta que una conformidad restaurativa no podría aplicarse a los casos de violencia de género, por los que el legislador ha (curiosamente) permitido la conformidad ${ }^{114}$ pero prohibido la mediación ${ }^{115}$.

113 RODRIGUEZ PUERTA, M.J: "El derecho de las víctimas colectivas a participar en encuentros restaurativos. Un análisis a partir de algunos delitos económicos", en prensa en RECPC - Revista Electrónica de Ciencia Penal y Criminología (aceptado el 12 de noviembre 2020).

114 En 2018, la conformidad se ha alcanzado en el 58,60\% de los casos de violencia de género. Vid. FISCALÍA GENERAL DEL ESTADO, 2019, cit.

115 Así también lo señala Gómez Colomer, quien se inclina por prohibir la conformidad, además de la mediación, en estos casos. Vid. GÓMEZCOLOMER, 2012, cit. 
Por otro lado, debería regularse el tema de la responsabilidad civil. Aguilera Morales advierte que "enarbolar la bandera de la Justicia Restaurativa" no tendría sentido a menos de subordinar los beneficios que derivan de la conformidad a la satisfacción efectiva de la responsabilidad civil o a la constatación de que el acusado se ha esforzado por reparar a la víctima ${ }^{116}$. Ello quizás resultaría en un tratamiento desigual de los acusados que no dispongan de medios económicos suficientes. En todo caso, debería reconocerse más valor a los acuerdos simbólicos alcanzados en el encuentro restaurativo como fórmula para satisfacer la responsabilidad civil, además de como criterios de referencia para la aplicación de la atenuante de reparación.

Finalmente, sería necesario prever qué consecuencias podría tener una sentencia de conformidad restaurativa sobre la misma ejecución de la pena. Es decir, si debería o no tenerse en cuenta como indicador favorable para el acceso a los beneficios penitenciarios el hecho de haber participado en un encuentro restaurativo en fase de enjuiciamiento ${ }^{117}$.

\section{Conclusiones}

En este trabajo hemos querido explorar la posibilidad de impulsar un modelo restaurativo de conformidad. Para ello, ha sido necesario analizar algunos mecanismos de justicia negociada vigentes tanto en contextos anglosajones como en derecho continental y profundizar en sus aspectos más problemáticos. Hemos averiguado que la lógica instrumental y la falta de transparencia en la que se basa la justicia negociada desencadena numerosos efectos negativos: para el acusado en términos de garantías penales y procesales, para la víctima en términos de su exclusión y subordinación y

116 AGUILERA MORALES, 2017, cit., pp. 116-117

117 Se trata de una cuestión problemática señalada por algunos de nuestros entrevistados 
para el sistema en su conjunto en términos de coherencia y credibilidad.

Hemos definido cómo se articula el principio del consenso en la justicia negociada y en la justicia restaurativa, para señalar la necesidad de promover mecanismos procesales basados en un consenso restaurativo. En este sentido, hemos caracterizado el consenso negociado como mera adhesión a una propuesta ajena en el marco de una relación asimétrica, poniendo en evidencia cómo esto es inherente a la lógica instrumental que gobierna la justicia negociada y contribuye a producir efectos negativos. Por el otro lado, hemos conceptualizado el consenso restaurativo como el acto de consensuar en el marco de una relación relativamente simétrica, para identificar cooperativamente la mejor forma de reparar el daño provocado por el delito. Ello nos ha permitido argumentar en favor de este tipo de consenso, dado que responde mejor que el consenso negociado a las exigencias tanto del sistema de justicia, como de todos los actores involucrados en el evento delictivo.

Es en virtud de ello que proponemos la aplicación del principio del consenso restaurativo a la conformidad y, a partir de ahí, la utilización "mestiza" de este mecanismo procesal, para que los fundamentos del proceso penal y de la justicia restaurativa puedan integrarse sin perder su naturaleza típica.

Ahora bien, como he anticipado, la puesta en marcha de una conformidad restaurativa debería servir únicamente para adelantar el ingreso de los principios restaurativos en el sistema de justicia penal actual, mientras aguardamos una reforma que tarda en concretarse. La modificación restaurativa de la LECrim debería en efecto extenderse mucho más allá y concretarse en una ley dedicada a la justicia restaurativa, caracterizada por una regulación abierta de los procesos restaurativos, que sepa tutelar las garantías procesales de los acusados y al mismo tiempo asegurar la autodeterminación 
de las partes, potenciando las intervenciones tempranas, incluidas las extrajudiciales. De todos modos, si el próximo proyecto de reforma, como es probable, no contemplara la renuncia a la conformidad y a sus supuestos beneficios "agilizadores", deberían al menos tenerse en cuenta las advertencias formuladas en este trabajo y abogar por modular este dispositivo negocial según una orientación restaurativa.

\section{Bibliografía}

AGUILERA MORALES, Marien: "Víctima y conformidad: Al encuentro de dos rectas paralelas llamadas a coincidir", en DE HOYOS SANCHO, Montserrat: La víctima del delito y las últimas reformas procesales penales, Aranzadi, Pamplona, 2017, pp. 99-119.

AMBOS, K. et al. (2020): Core Concepts in Criminal Law and Criminal Justice: Anglo-German Dialogues, Volume 1, Cambridge: Cambridge University Press, 2020.

BONAFÉ-SCHMITT, J.-P.: "Les médiations", en Communication et organisation, n. 11, 1997, disponible en: $\mathrm{Http} / / /$ communicationorganisation.revues.org/1914

BONAFÉ-SCHMITT, J.-P.: "Los mediadores: el actuar comunicacional”, en La Trama, n. 18, 2006.

CARABANTE MUNTADA, J. M.: "La teoría de la acción comunicativa como modelo de mediación", en RODRÍGUEZ-ARANA MUÑOZ, X. / DE PRADA RODRÍGUEZ, Mercedes (coords.), La mediación: presente, pasado y futuro de una institución jurídica (3546), España: Netbliblo, 2010, pp. 35-46, p. 46.

CECANESE, G.: "Ancora dubbi irrisolti in tema di applicazione della pena su richiesta delle parti”, en Archivio Penale, n. 1, 2015, pp. 1-25, p. 22.

CHAMBAZ, Christine (dir.): Les chiffres-clés de la Justice 2018. Ministère de la Justice, Sous-direction de la Statistique et des Études, Paris, 2018, disponible en: 
http://www.justice.gouv.fr/art_pix/justice-chiffrescles-2018.pdf

CHEESMAN, Samantha. J.: "Comparative Perspectives on Plea Bargaining in Germany and the U.S.A.", en BADÓ, A. / BELLING, D.W (Eds). Rechtsentwicklungen aus europäischer Perspektive im 21. Jahrhundert, Potsdam: Universität Potsdam, 2014, pp. 113151, disponible en: https://publishup.uni-potsdam.de/ opus4-ubp/frontdoor/deliver/index/docId/7046/file/ aiup02.pdf

COMUNICACIÓN PODER JUDICIAL (7 de abril de 2020). El CGPJ reúne un centenar de medidas en un documento base preparatorio del plan de choque para evitar el colapso de la Justicia tras el fin del estado de alarma. Disponible en: http://www.poderjudicial.es/ cgpj/es/Poder-Judicial/En-Portada/El-CGPJ-reuneun-centenar-de-medidas-en-un-documento-base-preparatorio-del-plan-de-choque-para-evitar-el-colapsode-la-Justicia-tras-el-fin-del-estado-de-alarma.

CRESPO, A.M.: "The Hidden Law of Plea Bargaining", en Columbia Law Review, n. 118, 2018, pp. 1303-1424.

DAVIS, Angela J.: "In Search of Racial Justice: The Role of The Prosecutor.", en Legislation and Public -Policy, n. 16, 2013, pp. 821-851.

DAVIS, Angela J.: "The Prosecutor's Ethical Duty to End Mass Incarceration", en Hofstra Law Review, Vol. 44, n. 4, 2016, pp. 1063-1085.

DAVIS, Angela J.: "Prosecution and Race: The Power and Privilege of Discretion", en Fordham Law Review, Vol. 67, n. 1, 1998, pp. 13-68.

DEDIEU, J.-P. (1992): "Denunciar-denunciarse. La delación inquisitorial en Castilla la Nueva en los siglos XVIXVII", en Revista de la Inquisición, n. 2, 1992, pp. 95108.

FERNANDEZ-BERTIER, M.: "The extension of the Belgian criminal transaction as a new mean to fight 
economic and financial crime: towards the establishment of plea bargaining?" En NEVES CRUZ, J. et.al. (Coords.): Infrações económicas e financeiras : estudos de criminologia e direito, Coimbra : Coimbra Editora, 2013, pp. 484-494.

FERRÉ OLIVÉ, J.C.: "El Plea Bargaining, o cómo pervertir la justicia penal a través de un sistema de conformidades low cost", en Revista Electrónica de Ciencia Penal y Criminología, 20-06, 2018, pp. 1-30.

FISCALÍA GENERAL DEL ESTADO: Instrucción 2/2009 sobre Aplicación del protocolo de conformidad suscrito por la Fiscalía General del Estado y el Consejo General de la Abogacía española, disponible en http://www.poderjudicial.es/cgpj/es/Temas/Relaciones-institucionales/ Convenios/Protocolo-de-actuacion-para-juicios-deconformidad-suscrito-entre-la-Fiscalia-General-delEstado-y-el-Consejo-General-de-la-Abogacia-espanola.

FISCALÍA GENERAL DEL ESTADO: Memoria de la FGE 2019, Madrid.

FLYNN, Asher / FREIBERG, A.: Plea negotiations. Pragmatic Justice in an Imperfect World, Palgrave Socio-Legal Studies, 2018.

FROMMANN, Maike: "Regulating Plea-Bargaining in Germany: Can the Italian Approach Serve as a Model to Guarantee the Independence of German Judges?", en Hanse Law Review, Vol. 5, n. 1, 2009, pp. 197-220.

GADDI, Daniela: La mediación reflexiva como mecanismo de regulación social (Tesis doctoral). Barcelona: Universitat Autònoma de Barcelona, 2017, ISBN 9788449068720. Disponible en https://ddd.uab.cat/record/174014

GALLI, Martina: "Une justice pénale propre aux personnes morales. Réflexions sur la convention judiciaire d'intérêt public", en Revue de science criminelle et de droit pénal comparé, Vol. 2, n. 2, 2018, pp. 359-385. 
GÓMEZ COLOMER, J.-L.: "Notas sobre la justicia procesal (alternativa, negociada, transaccional, activa reparadora). Un nuevo sistema de justicia para aliviar al sistema de justicia judicial", en CASTILLEJO MANZANARES, Raquel (Dir.): Justicia restaurativa y violencia de género. Más allá de la Ley Orgánica 1/2004, Universidad de Santiago de Compostela, 2014, pp. 170-199.

GÓMEZ-COLOMER, J.-L.: "La conformidad, institución clave y tradicional de la justicia negociada en España", en Revue Internationale de Droit Pénal, Vol. 83, n. 1, 2012, pp. 15-41, disponible en: https://www.cairn. info/revue-internationale-de-droit-penal-2012-1-page-15.htm\#

HABERMAS, J.: Facticidad y validez., Ed. Trotta, Madrid, 1998 (ed. or. 1992-1994), pp. 234-235.

HABERMAS, J.: On the Pragmatics of Communication, The MIT Press, Cambridge, 1998 (ed. por COOKE Maeve)

HABERMAS, J.: Teoría de la Acción Comunicativa, Vol. I, Ed. Taurus: Madrid, 1987.

HABERMAS, J.: Verdad y justificación, Ed. Trotta Madrid, 2002 (ed. or. 1999).

HOULETTE, Éliane: "Des dispositifs répressifs innovants: la convention judiciaire d'intérêt public, le monitoring, la peine de programme de mise en conformité", en Actes de Colloque De la conformité à la justice négociée, actualité de la lutte anticorruption, École Nationale de la Magistrature, Paris, 17 de mai 2018, pp. 41-42. Disponible en: https://www.enm.justice.fr/ sites/default/files/actu-pdf/Actes-du-colloque_De-laconformite-a-la-justice-negociee.pdf

HOULLE, R. / VANEY, G.: "La comparution sur reconnaissance préalable de culpabilité, une procédure pénale de plus en plus utilisée », en INFOSTAT JUSTICE, n. 157, 2017, pp. 1-8, disponible en: http://www.justice. gouv.fr/art_pix/stat_Infostat_157.pdf 
IGARTUA LARAUDOGOITIA, Idoia: "Significación de la reparación, compensación o restauración en la administración de justicia penal. Retórica y práctica de la justicia penal negociada y la justicia penal restaurativa", en Revista Aranzadi Unión Europea, 10, 2016, pp. 65-84.

JOHNSON, Thea: "Public perceptions of plea bargaining", en American Journal of Criminal Law, Vol. 46, Fasc. 1, 2019, pp. 133-156.

KASSIN, S. M.: "False confessions: From colonial Salem, through Central Park, and into the twenty-first century", en WILLIS-ESQUEDA, Cinthia / BORNSTEIN, B.H (Eds.), The witness stand and Lawrence $S$. Wrightsman, Jr, Springer Science + Business Media, New York, 2016, pp. 53-74.

KING, C. I LORD, N.: Negotiated Justice and Corporate Crime. The Legitimacy of Civil Recovery Orders and Deferred Prosecution Agreements, Palgrave Pivot, 2018. LANGER, M.: "Plea Bargaining, Conviction Without Trial, and the Global Administratization of Criminal Convictions", en Annual Review of Criminology, $\mathrm{n}$. 4, 2021, pp. 1.1-1.35, review in advance disponible en: https://www.annualreviews.org/doi/pdf/10.1146/annurev-criminol-032317-092255

LE PROCUREUR DE LA REPUBLIQUE FINANCIERE, AGENCE FRANÇAISE ANTICORRUPTION: Lignes directrices sur la mise en ouvre de la Convention Judiciaire d'Intérêt Public, 2019, disponible en: https:// www.agence-francaise-anticorruption.gouv.fr/files/ files/Lignes $\% 20$ directrices $\% 20$ PNF $\% 20$ CJIP.pdf

LESTER, B.J.: "System Failure: The Case for Supplanting Negotiation with Mediation in Plea Bargaining", en Ohio State Journal on Dispute Resolution, Vol. 20, n. 2, 2005, pp. 563-595.

LORUSSO, S.: "Il processo penale italiano tra prassi e consuetudine", en: MILETTI, M. N. (Ed.). Riti, tecniche, 
interessi: il processo penal tra Otto e Novecento (531542). Milano: Giuffrè, 2006.

MANNOZZI, Grazia: "Il crimine dei colletti bianchi: profili definitori e strategie di contrasto attraverso i metodi della giustizia riparativa", en SPINELLIS, Calliope D. / THEODORAKIS, N. / BILLIS, E. / PAPADIMITRAKOPOULOS, G. (Eds). Europe in crisis: crime, criminal justice, and the way forward. Essays in honour of Nestor Courakis. Vol. II, Ant. N. Sakkoulas Publishers L.P., Athens, 2017, pp. 1365-1394.

MAZZACUVA, F.: "Justification and Purposes of Negotiated Justice for Corporate Offenders: Deferred and Non-Prosecution Agreements in the UK and US Systems of Criminal Justice", en The Journal of Criminal Law, n. 78, 2014, pp. 249-262.

NADER, Laura: "The ADR Explosion - The Implications of Rhetoric in Legal Reform", en Windsor Yearbook of Access to Justice, n. 8, 1988, pp. 269-281.

NICOLINI, N.: Storia de' principii regolatori della istruzione delle pruove ne' processi penali. Della procedura penale nel regno delle Due Sicilie, Napoli.

NIEMI, J. I.: "Jürgen Habermas's theory of communicative rationality: the foundational distinction between communicative and strategic action", en Social Theory and Practice, Vol. 31, n. 4, 2005, pp. 513-532.

PASCUAL RODRÍGUEZ, Esther: "La experiencia práctica de la mediación penal en Madrid", en MARTÍNEZ ESCAMILLA, Margarita; SÁNCHEZ ÁLVAREZ, María Pilar (Coords.). Justicia restaurativa, acción penal y penitenciaria: un renovado impulso, Madrid, Reus, 2011, pp. 361-392.

PERONI, F.: "La peripezia del patteggiamento in un trentennio di sperimentazione", en Archivio Penale, n. 3, 2019, pp. 1-23

RODRÍGUEZ ARIAS, A.M.: "Principio de oportunidad, justicia negociada y posición de las partes en el 
proceso penal", en Revista de Derecho y Proceso Penal, n. 56, 2019, pp. 161-198.

RODRÍGUEZ GARCÍA, N.: "Aproximación al estudio de la justicia penal negociada de los EE.UU.: The Plea Bargaining Process", en REDEN: Revista Española De Estudios Norteamericanos, n. 9, 1995, pp. 91-107.

RODRÍGUEZ PUERTA, María José. "El derecho de las víctimas colectivas a participar en encuentros restaurativos. Un análisis a partir de algunos delitos económicos” EN RECPC - Revista Electrónica de Ciencia Penal y Criminología, en prensa (aceptado el 12 de noviembre de 2020).

SWANSON, T.: "The German 'Plea Bargaining' Debate”, en Pace International Law Review, Vol. 7, n. 2, 1995, pp. 373-429, disponible en: https://digitalcommons.pace. edu/pilr/vol7/iss $2 / 4$

TEN BOOM, Annemarie; KUIJPERS, Karlijin F.: "Victims' needs as basic human needs", en International Review of Victimology, Vol. 18, n. 2, 2012, pp. 155-179.

TIGANO, Marta: "La giustizia ecclesiastica del Cinquecento", en VERGENTIS, n. 5, 2017, pp. 221-239.

VARONA, Gemma: "Justicia restaurativa y justicia terapéutica: hacia una praxis reflexiva de transgresiones disciplinares", en PILLADO GONZÁLEZ, Esther (Dir.): Hacia un proceso penal más reparador y resocializador: avances desde la justicia terapéutica, Dickynson, Madrid, 2019, pp. 25-55.

VERDUN-JONES, S.N. / TIJERINO, Adamira A.: "Four Models of Victim Involvement during Plea Negotiations: Bridging the Gap between Legal Reforms and Current Legal Practice", en Revue Canadienne de Criminologie et de Justice Penal, Vol. 46, n. 4, 2004, pp. 471-500.

VERGES, E.: "Procédure pénale", en Revue de science criminelle et de droit pénal comparé, Vol. 3, n. 3, 2017, pp. 579-586. 
VERGINE, F.:"Il patteggiamento: gli obblighi restitutori depotenziano le finalità deflattive", en Processo penale e giustizia, n. 2, 2019, pp. 443-449.

WEIGEND, T. / TURNER, Jenia I.: "The Constitutionality of Negotiated Criminal Judgments in Germany", en German Law Journal, Vol. 15, n. 1, 2014, pp. 81-105.

XIAO, M. Y.: "Deferred/Non Prosecution Agreements: Effective Tools to Combat Corporate Crime", en Cornell Journal of Law and Public Policy, Vol. 23, n.1, Article 7, 2013, pp. 233-253. Disponible en: http://scholarship. law.cornell.edu/cjlpp/vol23/iss1/7 